\title{
Nucleic Acid Conformation Influences Postsynthetic Suzuki-Miyaura Labeling of Oligonucleotides
}

Manisha B. Walunj and Seergazhi G. Srivatsan*

Department of Chemistry, Indian Institute of Science Education and Research (IISER), Pune Dr. Homi Bhabha Road, Pune 411008, India. E-mail: srivatsan@iiserpune.ac.in

\section{Supporting Information}

1. Materials: 5-Iodo-2'-deoxyuridine (1) was purchased from TCI Chemicals (India) Pvt. Ltd. DMTr-Cl, $N, N$-diisopropylethylamine, benzofuran boronic acid a, 2-cyanoethyl $N, N$ diisopropylchlorophosphoramidite, 2-aminopyrimidine-4,6-diol (ADHP, L) and $\mathrm{Pd}(\mathrm{OAc})_{2}$ were purchased from Sigma Aldrich. DMAP was purchased from Alfa Aesar. $N, N$ dimethylformamidine-protected $\mathrm{dG}, N$-benzoyl-protected $\mathrm{dA}$ and $\mathrm{dT}$ phosphoramidite substrates for solid-phase oligonucleotide $(\mathrm{ON})$ synthesis were purchased from ChemGenes

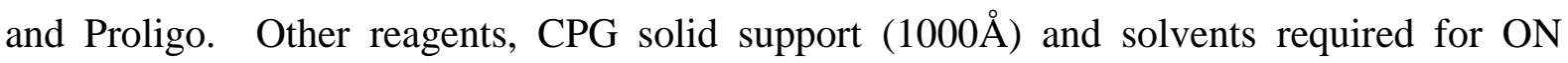
synthesis were purchased either from ChemGenes or Sigma-Aldrich. Native G-rich (18-20) and $\mathrm{C}$ rich (21) DNA ONs were purchased from Integrated DNA Technologies, Inc., and purified by polyacrylamide gel electrophoresis (PAGE) using urea as the denaturing agent. ONs were desalted using Sep-Pak Classic C18 cartridges (Waters Corporation). Autoclaved water was used in buffer preparation and in postsynthetic Suzuki reactions.

2. Instrumentation: NMR spectra were recorded on a $400 \mathrm{MHz}$ Jeol ECS-400 and Bruker Avance III HD Ascend $400 \mathrm{MHz}$ spectrometer and were processed using Mnova NMR software. IdU-modified DNA ONs were synthesized on an Applied Biosystems RNA/DNA synthesizer (ABI-394). Mass measurements were performed using Applied Biosystems 4800 Plus MALDI TOF/TOF analyzer and ESI-MS Waters Synapt G2-Si Mass Spectrometry instrument. RP-HPLC analysis of ONs was performed using Phenomenex-Luna C18 column (250 x $4.6 \mathrm{~mm}, 5$ micron) on an Agilent Technologies 1260 Infinity HPLC. Absorption spectra were recorded on a Shimadzu spectrophotometer. UV-thermal melting analysis of ONs was performed on a Cary 300 Bio UV-Vis spectrophotometer. CD spectra were recorded using JASCO-J-815 CD spectrometer. Fluorescence experiments were carried out in a micro fluorescence cuvette (Hellma, path length $1.0 \mathrm{~cm}$ ) on a Horiba Jobin Yvon, Fluoromax-4. 


\section{Synthesis of 5-iodo-modified uridine phosphoramidite substrate 3}

5-Iodo-5'-DMT-protected-2'-deoxyuridine 2: ${ }^{\mathrm{S} 1}$ 5-Iodo-2'-deoxyuridine 1 (1 g, 2.82 mmol, 1 equiv.), DMAP (172 mg, 1.41 mmol, 0.5 equiv.), DMTrCl (1.43 g, 4.24 mmol, 1.5 equiv.) were taken in a round bottom flask. Dry pyridine $(30 \mathrm{~mL})$ was added to it and reaction mixture was stirred at room temperature (RT) overnight. After completion of the reaction, solvent was evaporated under vасио. The crude residue was purified by column chromatography to afford the pure compound 2 as an off-white solid. (1.35 g, 70\%). TLC $\left(\mathrm{MeOH}: \mathrm{CHCl}_{3}=5: 95\right.$ containing few drops of $\left.\mathrm{Et}_{3} \mathrm{~N}\right) ; R_{f}=0.33 ;{ }^{1} \mathrm{H} \mathrm{NMR}\left(400 \mathrm{MHz}, \mathrm{CDCl}_{3}\right)$ $\delta(\mathrm{ppm}) 8.11(\mathrm{~s}, 1 \mathrm{H}), 7.42(\mathrm{~d}, J=8 \mathrm{~Hz}, 2 \mathrm{H}), 7.34-7.28(\mathrm{~m}, 6 \mathrm{H}), 7.23-7.20(\mathrm{~m}, 1 \mathrm{H}), 6.85-$ $6.83(\mathrm{~m}, 4 \mathrm{H}), 6.34(\mathrm{dd}, J=5.8,7.8 \mathrm{~Hz}, 1 \mathrm{H}), 4.57-4.55(\mathrm{~m}, 1 \mathrm{H}), 4.12-4.11(\mathrm{~m}, 1 \mathrm{H}), 3.79(\mathrm{~s}$, $6 \mathrm{H}), 3.37(\mathrm{~s}, 2 \mathrm{H}), 2.53-2.48(\mathrm{~m}, 1 \mathrm{H}), 2.29-2.23(\mathrm{~m}, 1 \mathrm{H}) ;{ }^{13} \mathrm{C} \mathrm{NMR}\left(100 \mathrm{MHz}, \mathrm{CDCl}_{3}\right) \delta$ $(\mathrm{ppm})=158.64,144.42,144.18,135.61,135.60,135.43,130.14,130.10,128.09,127.02$, 113.37, 86.95, 86.42, 85.51, 72.20, 63.68, 55.29, 41.54. HRMS (m/z): Calculated for $\mathrm{C}_{30} \mathrm{H}_{29} \mathrm{IN}_{2} \mathrm{O}_{7} \mathrm{Na}[\mathrm{M}+\mathrm{Na}]^{+}=679.0917$, found: 679.0916 .

5-Iodo-2'-deoxyuridine phosphoramidite substrate 3: We employed a literature report to synthesize compound 3. ${ }^{\mathrm{S} 1}$ 5-Iodo-5'-DMT-protected-2'-deoxyuridine 2 (328 mg, $0.5 \mathrm{mmol}, 1$ equiv.) was dissolved in dry DCM (4 mL). To this clear solution, diisopropylethylamine (523 $\mu \mathrm{L}, 3 \mathrm{mmol}, 6$ equiv.) was added and stirred for $30 \mathrm{~min}$ at RT. 2-cyanoethylchloro- $N, N$ diisopropylphosphoramidite (167 $\mu \mathrm{L}, 0.75 \mathrm{mmol}, 1.5$ equiv.) was added slowly under nitrogen. The reaction mixture was stirred for $1 \mathrm{~h}$ under nitrogen atmosphere at RT. Reaction mixture was evaporated under vacuum and the residue was purified by column chromatography to afford product $\mathbf{3}$ as an off-white foam. (316 $\mathrm{mg}, 75 \%$ ) TLC (acetone:cyclohexane $=40: 60$ containing few drops of $\left.\mathrm{Et}_{3} \mathrm{~N}\right) ; R_{f}=0.47 ;{ }^{1} \mathrm{H} \mathrm{NMR}(400 \mathrm{MHz}$, $\left.\mathrm{CDCl}_{3}\right) \delta(\mathrm{ppm})($ diastereomers ratio $=1: 0.5) ;{ }^{1} \mathrm{H}$ NMR for major diastereomer: $8.14(\mathrm{~s}, 1 \mathrm{H})$, 7.42 (br.s, 2H), 7.32 (br.s, 6H), 7.24 (br.s, 1H), 6.86-6.84 (m, 4H), 6.31 (br.s, 1H), 4.62 (br.s, $1 \mathrm{H}), 4.21(\mathrm{~s}, 1 \mathrm{H}), 3.80(\mathrm{~s}, 6 \mathrm{H}), 3.64-3.53(\mathrm{~m}, 4 \mathrm{H}), 3.42-3.31(\mathrm{~m}, 2 \mathrm{H}), 2.70-2.68(\mathrm{~m}, 1 \mathrm{H})$, 2.62 (br.s, 2H), 2.31-2.28 (m, 1H), 1.17-1.06 (m, 12H); ${ }^{31} \mathrm{P}$ NMR (162 MHz, $\left.\mathrm{CDCl}_{3}\right): \delta$ (ppm) 149.55, 149.09; HRMS (m/z): Calculated for $\mathrm{C}_{39} \mathrm{H}_{46} \mathrm{IN}_{4} \mathrm{O}_{8} \mathrm{PNa}[\mathrm{M}+\mathrm{Na}]^{+}=879.1995$, found: 879.1996 . 
4. Solid-phase synthesis of IdU-labeled DNA ONs (4-17): IdU-modified H-Telo DNA ONs were synthesized on a $1000 \AA$ CPG solid support (1.0 $\mu$ mol scale). IdU phosphoramidite 3 was site-specifically introduced into the ONs by employing standard DNA ON synthesis protocol. After the final DMT deprotection step, the solid support was treated with 30\% aqueous solution of ammonium hydroxide at RT for $48 \mathrm{~h}$. Aqueous ammonium hydroxide solution was completely evaporated on a Speed Vac, and deprotected ON products were purified by denaturing $20 \%$ polyacrylamide gel electrophoresis. Respective modified ON products were visualized by UV shadowing and bands corresponding to full-length IdUmodified DNA ONs were excised from the gel using sterile scalpel and transferred to a PolyPrep column (Bio-Rad). The gel pieces were crushed well with a sterile glass rod and ONs were extracted using aqueous sodium acetate $(0.3 \mathrm{M}, 4 \mathrm{~mL})$ for $12 \mathrm{~h}$. The column was centrifuged and filtrate was desalted using Sep-Pak classic C18 cartridges (Waters). 

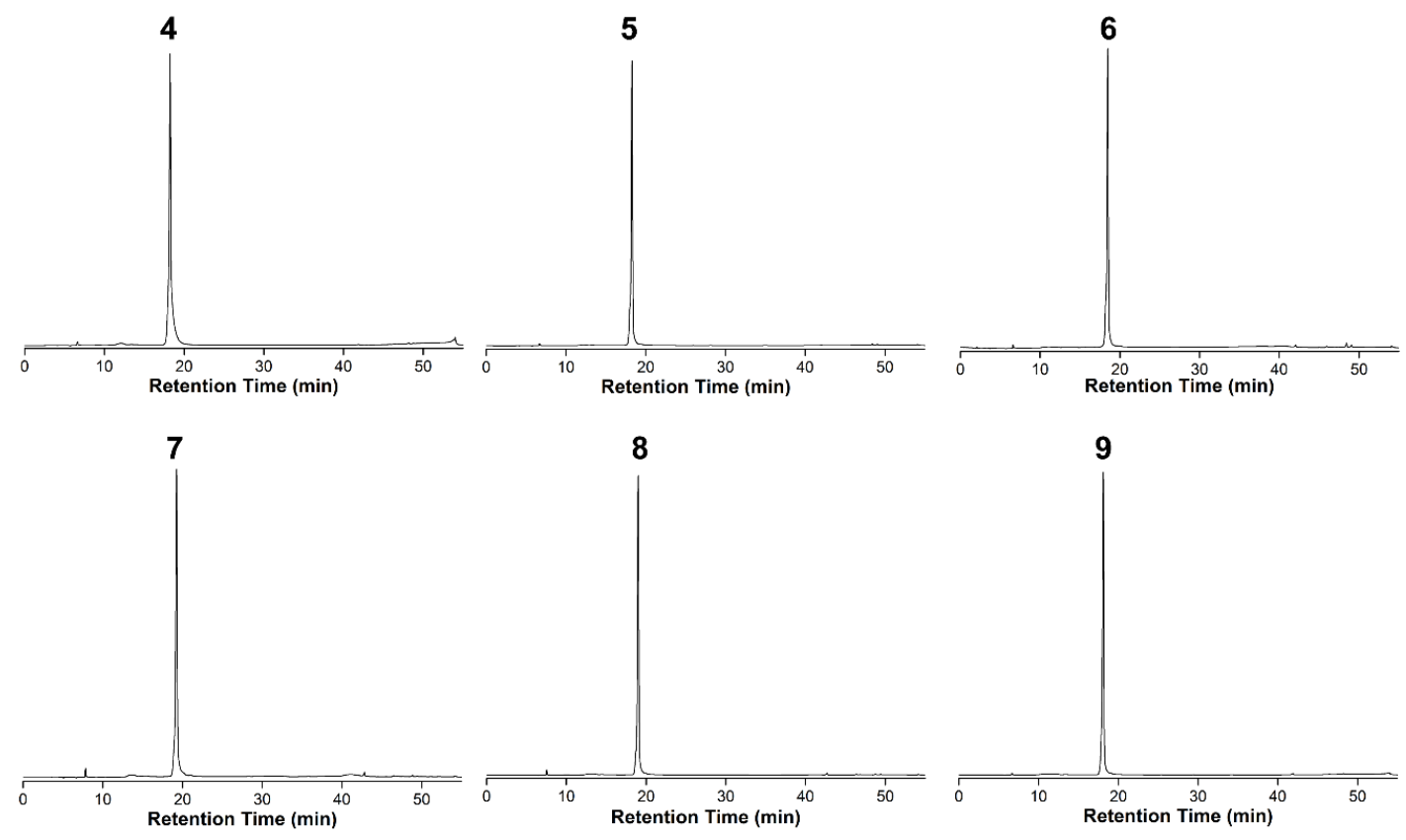

10

11

12
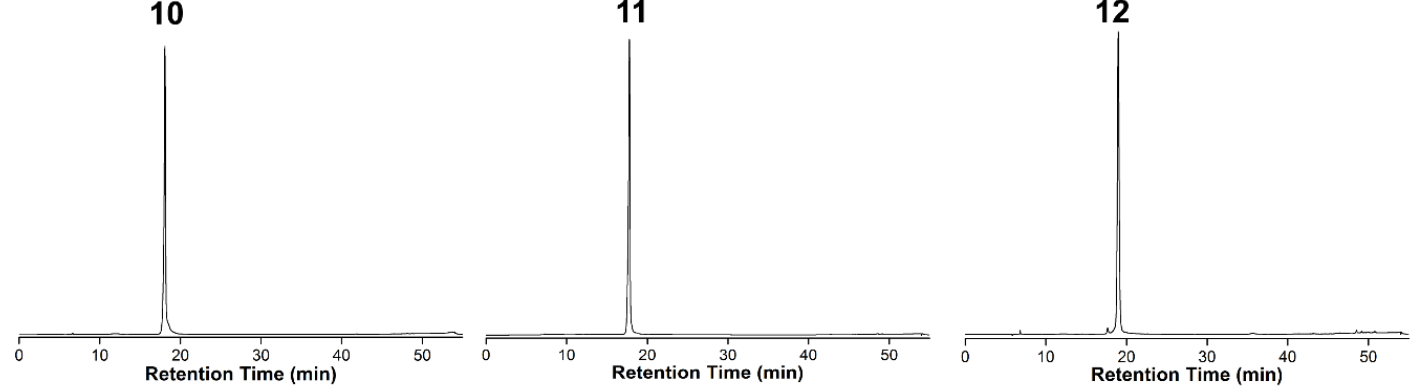

13
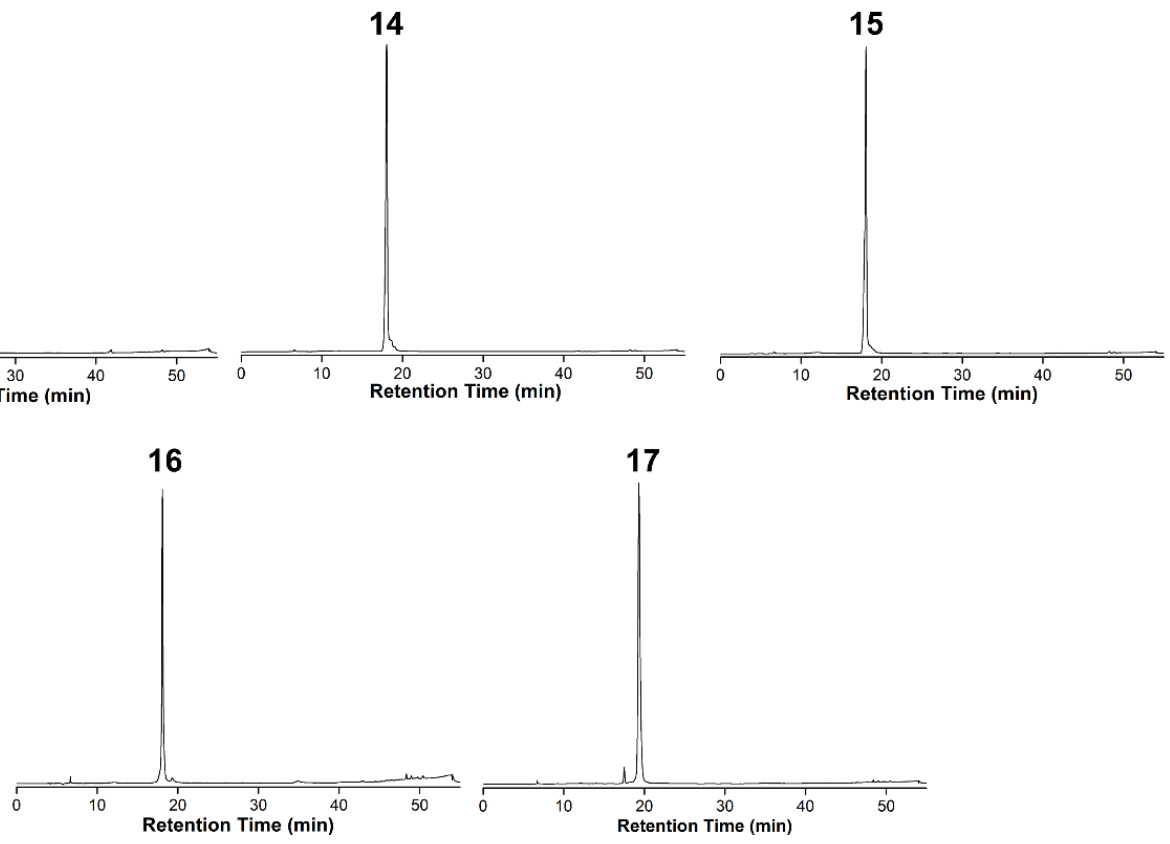

Figure S1. RP-HPLC chromatogram of PAGE purified IdU-labeled DNA ONs 4-17 at $260 \mathrm{~nm}$. Mobile phase A: $50 \mathrm{mM}$ TEAA buffer ( $\mathrm{pH} 7.0)$, mobile phase B: acetonitrile. Flow rate: $1 \mathrm{~mL} / \mathrm{min}$. Gradient: $0-30 \%$ B in 35 min, $30-100 \%$ B in 10 min and $100 \%$ B for 5 min. 


\section{Mass analysis of modified DNA ONs}

MALDI-TOF: Sample for mass analysis was prepared by combining $1 \mu \mathrm{L}$ of modified DNA ONs $(\sim 500 \mu \mathrm{M}), 3 \mu \mathrm{L}$ of DNA standard $(100 \mu \mathrm{M}, 18$-mer) and $5 \mu \mathrm{L}$ of a mixture of saturated 3-hydroxy picolinic acid and $100 \mathrm{mM}$ ammonium citrate buffer ( $\mathrm{pH}$ 9, in the ratio of 9:1). The sample was desalted using ion-exchange resin (Dowex 50W-X8, 100-200 mesh, ammonium cation form), spotted on the MALDI plate, and was air dried. Depending on the peak intensity the ratio of DNA ON and internal DNA standard (18 mer) was varied. All MALDI-TOF spectra were calibrated relative to the +1 and +2 ions of an internal 18 -mer DNA ON standard ( $\mathrm{m} / \mathrm{z}$ for +1 and +2 ions are 5466.6 and 2733.3 , respectively).

ESI-MS: ESI-MS analysis was performed in negative mode by injecting DNA ON (0.5 nmol) dissolved in 50\% acetonitrile containing an aqueous solution of $10 \mathrm{mM}$ triethylamine and 100 $\mathrm{mM}$ hexafluoro-2-propanol. 

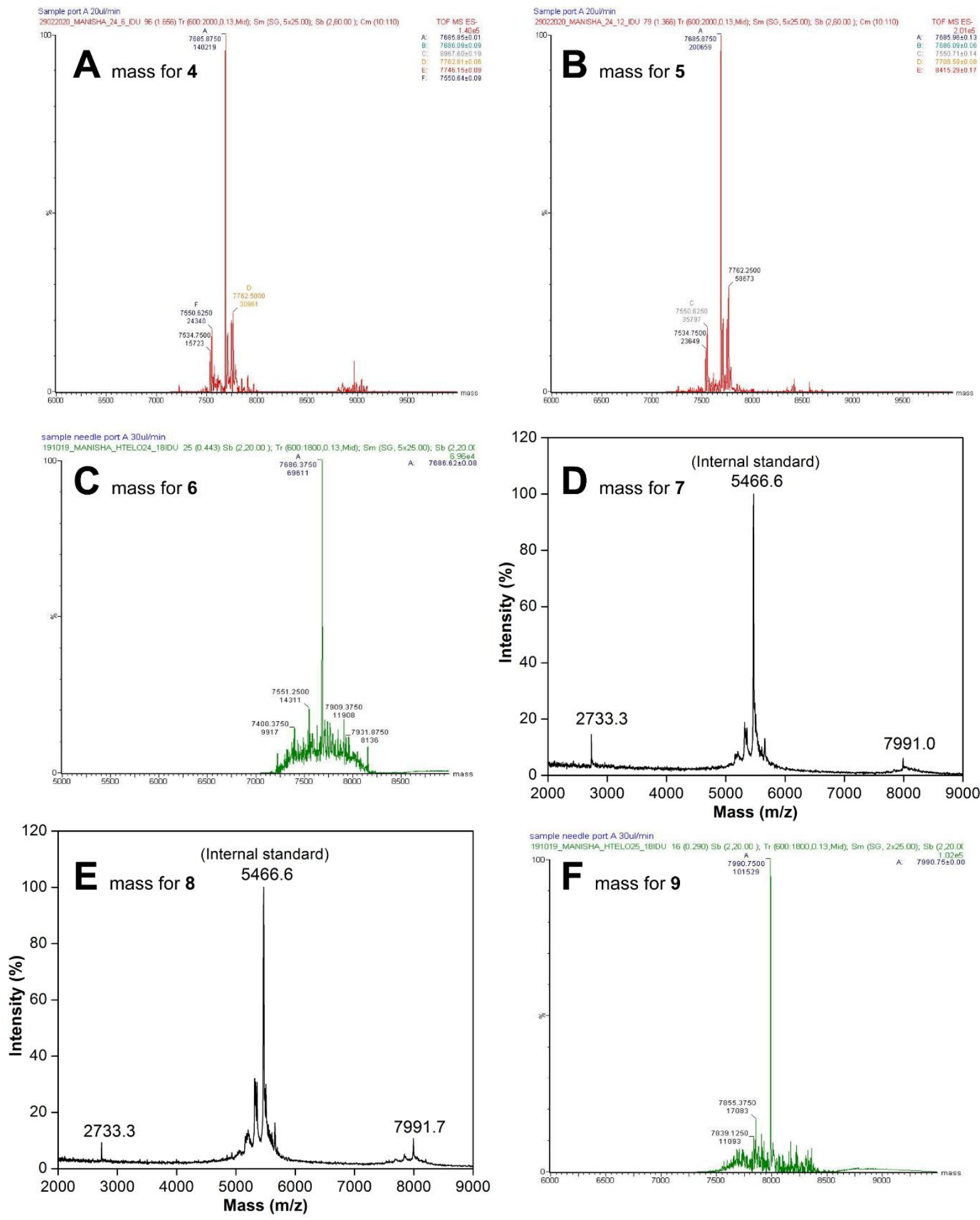

Figure S2. ESI-MS spectra of IdU-modified H-Telo DNA ONs (A) 4, (B) 5, (C) 6, (F) 9; MALDITOF spectra of IdU-modified H-Telo DNA ONs (D) 7, (E) 8. See section 5 and Table S1 for details. 

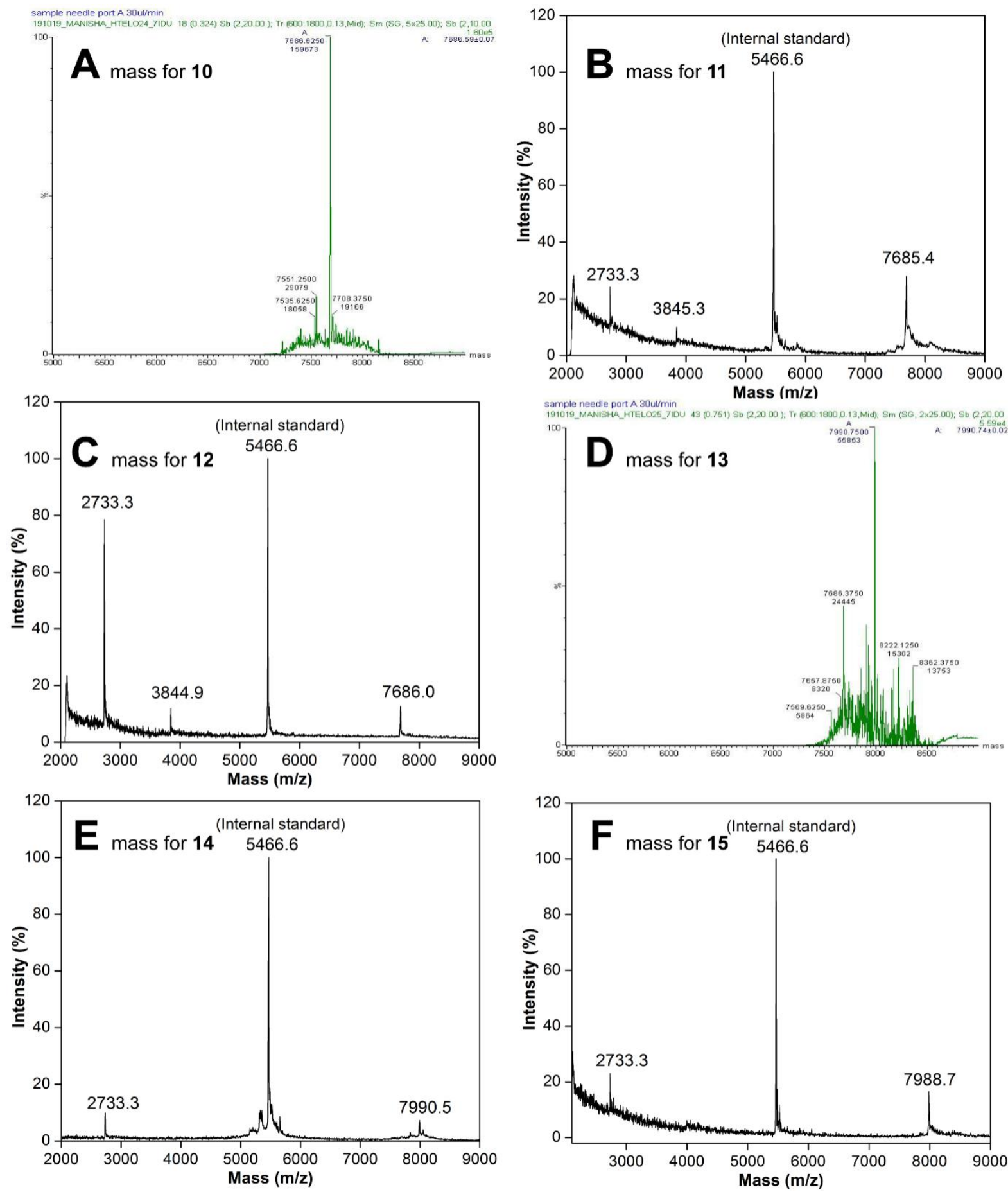

Figure S3. ESI-MS spectra of IdU-modified H-Telo DNA ONs (A) 10, (D) 13; MALDI-TOF spectra of IdU-modified H-Telo DNA ONs $(\mathbf{B}) \mathbf{1 1},(\mathbf{C})$ 12, (E) 14, (F) 15. See section 5 and Table S1 for details. 

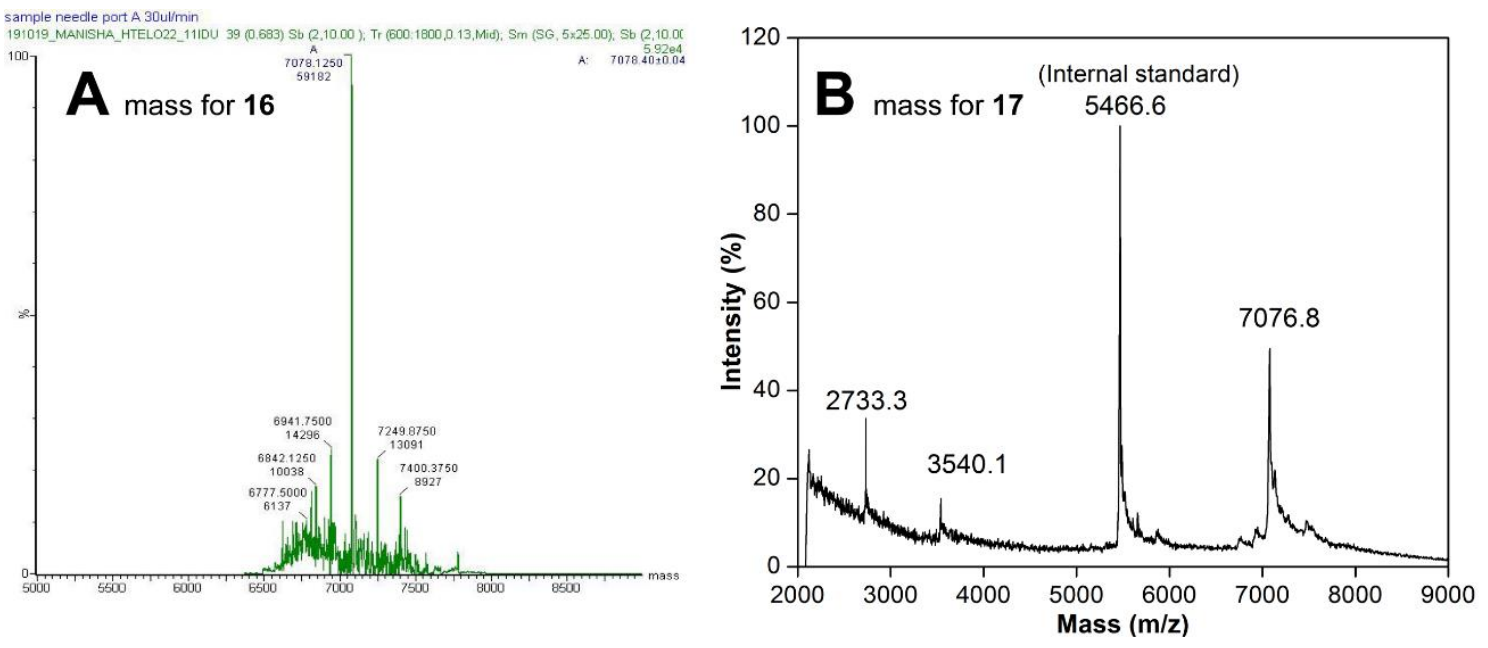

Figure S4. (A) ESI-MS spectrum of IdU-modified H-Telo DNA ON 16. (B) MALDI-TOF spectrum of IdU-modified H-Telo DNA ON 17. See section 5 and Table $\mathrm{S} 1$ for details.

Table S1. $\varepsilon_{260}$ and mass data for IdU-modified DNA ONs (4-17).

\begin{tabular}{cccc}
\hline IdU-modified DNA & $\varepsilon_{260}\left(\mathrm{M}^{-1} \mathrm{~cm}^{-1}\right)^{[\mathrm{a}]}$ & Calculated mass & Observed mass \\
\hline $\mathbf{4}$ & 238960 & 7685.8 & $7685.8^{[\mathrm{c}]}$ \\
$\mathbf{5}$ & 238960 & 7685.8 & $7686.0^{[\mathrm{c}]}$ \\
$\mathbf{6}$ & 238960 & 7685.8 & $7686.6^{[\mathrm{c}]}$ \\
$\mathbf{7}$ & 247760 & 7990.0 & $7991.0^{[\mathrm{b}]}$ \\
$\mathbf{8}$ & 247760 & 7990.0 & $7991.7^{[\mathrm{b}]}$ \\
$\mathbf{9}$ & 247760 & 7990.0 & $7990.7^{[\mathrm{c}]}$ \\
$\mathbf{1 0}$ & 238960 & 7685.8 & $7686.6^{[\mathrm{c}]}$ \\
$\mathbf{1 1}$ & 238960 & 7685.8 & $7685.4^{[\mathrm{b}]}$ \\
$\mathbf{1 2}$ & 238960 & 7685.8 & $7686.0^{[\mathrm{b}]}$ \\
$\mathbf{1 3}$ & 247760 & 7990.0 & $7990.7^{[\mathrm{c}]}$ \\
$\mathbf{1 4}$ & 247760 & 7990.0 & $7990.5^{[\mathrm{b}]}$ \\
$\mathbf{1 5}$ & 247760 & 7990.0 & $7988.7^{[\mathrm{b}]}$ \\
$\mathbf{1 6}$ & 223160 & 7077.4 & $7078.4^{[\mathrm{c}]}$ \\
$\mathbf{1 7}$ & 223160 & 7077.4 & $7076.8^{[\mathrm{b}]}$
\end{tabular}

${ }^{[\mathrm{a}]} \mathcal{E}_{260}$ of modified ONs was determined by using OligoAnalyzer 3.1. The extinction coefficient of nucleoside $1\left(\varepsilon_{260}=3360 \mathrm{M}^{-1} \mathrm{~cm}^{-1}\right)$ was used in place of thymidine $\left(\varepsilon_{260}=8700 \mathrm{M}^{-1} \mathrm{~cm}^{-1}\right)$.

${ }^{[\mathrm{b}]}$ MALDI-TOF. ${ }^{[\mathrm{c}]}$ ESI-MS. 

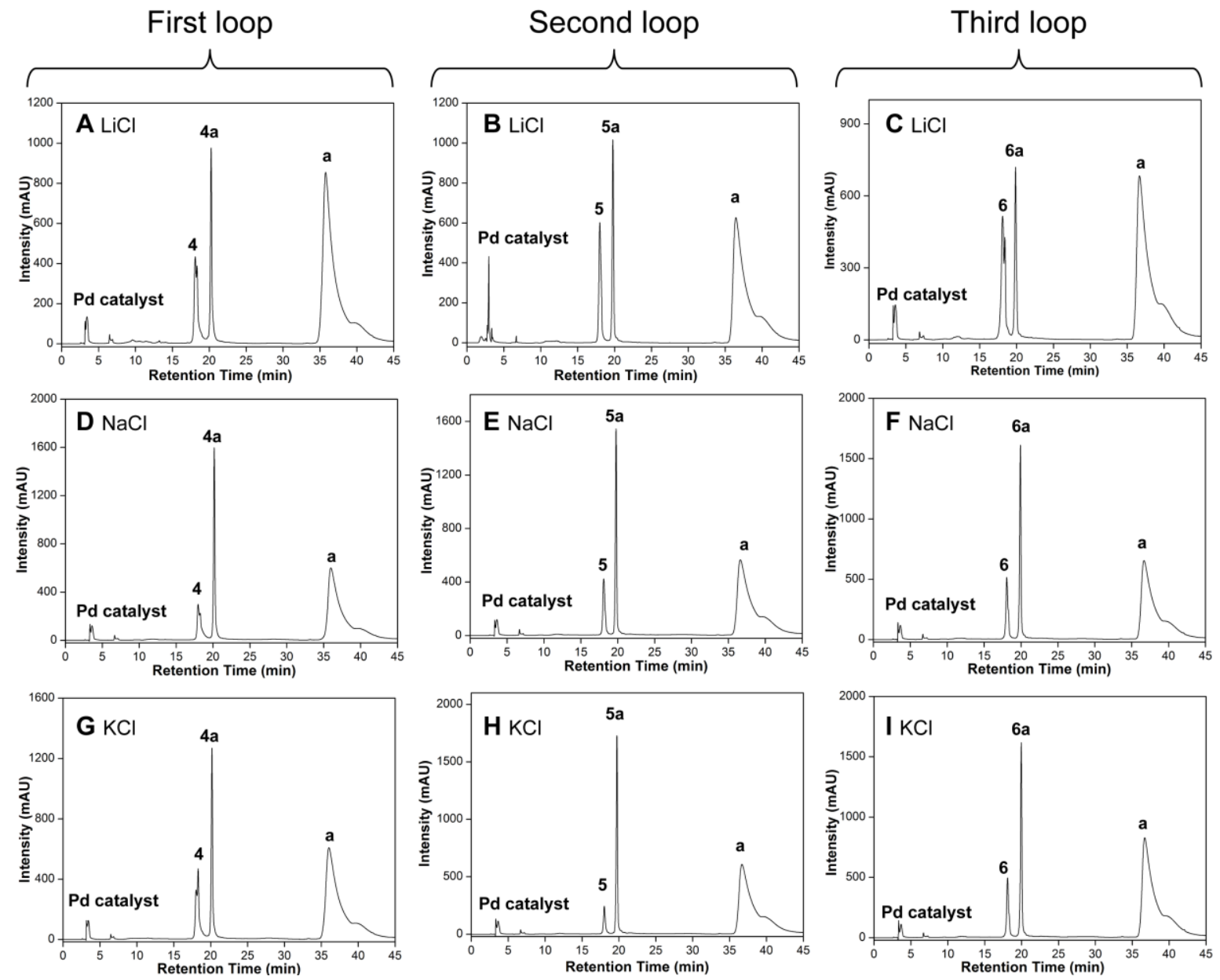

Figure S5. RP-HPLC chromatograms of reaction mixtures of postsynthetic Suzuki-Miyaura crosscoupling reactions on IdU-modified H-Telo-24 (IdU 1 incorporated at the $1^{\text {st }}$ dT position of each loop) DNA ON in the presence of $\mathrm{LiCl}$ (A) 4 (first loop), (B) $\mathbf{5}$ (second loop), (C) $\mathbf{6}$ (third loop); in the presence of $\mathrm{NaCl}$ (D) 4 (first loop), (E) 5 (second loop), (F) $\mathbf{6}$ (third loop) and in the presence of $\mathrm{KCl}$ (G) 4 (first loop), (H) 5 (second loop), (I) 6 (third loop). Peak 'a' corresponds to benzofuran boronic acid substrate. 

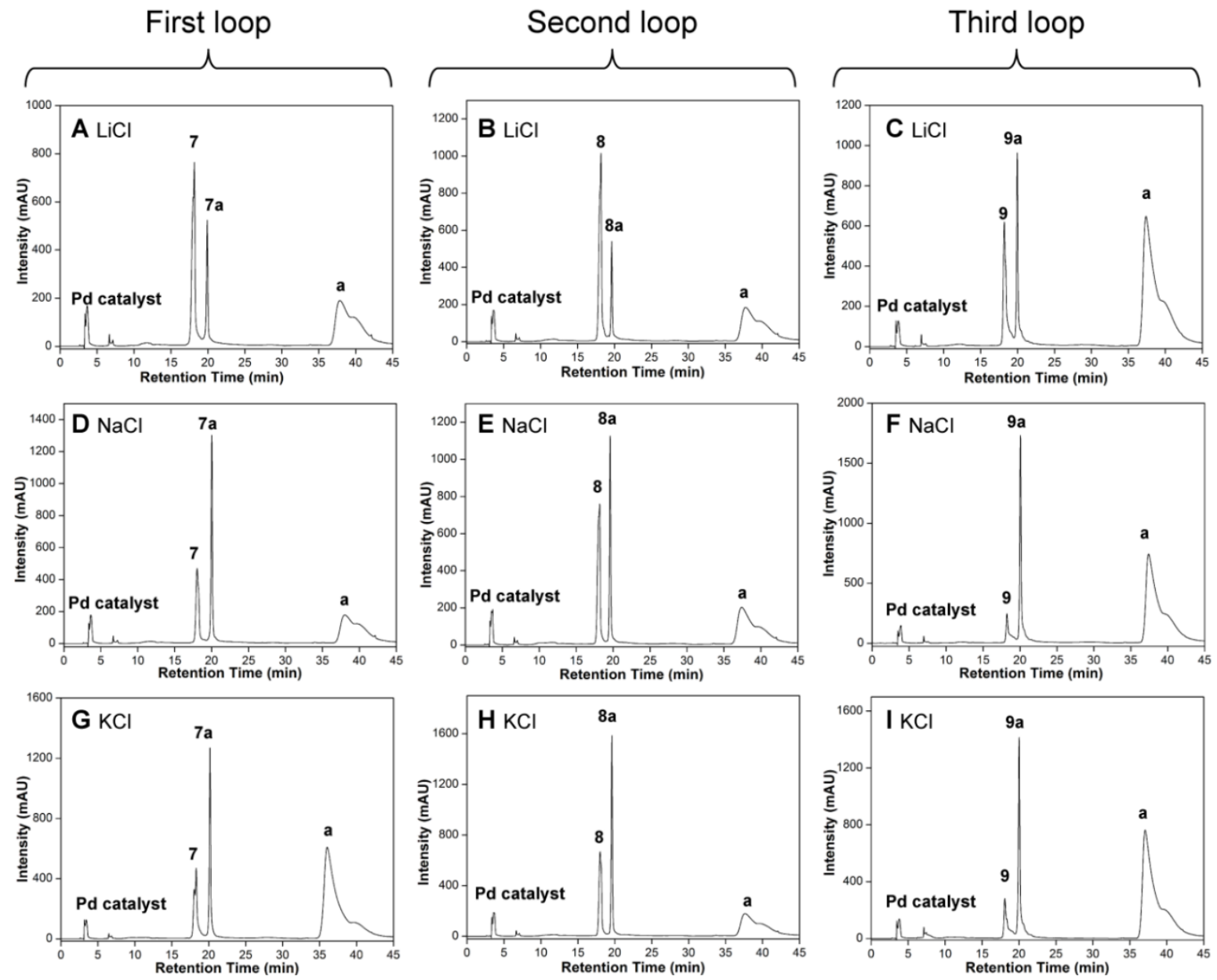

Figure S6. RP-HPLC chromatograms of reaction mixtures of postsynthetic Suzuki-Miyaura crosscoupling reactions on IdU-modified H-Telo-25 (IdU 1 incorporated at the $1^{\text {st }} \mathrm{dT}$ position of each loop) DNA ON in the presence of $\mathrm{LiCl}$ (A) 7 (first loop), (B) 8 (second loop), (C) 9 (third loop); in the presence of $\mathrm{NaCl}$ (D) 7 (first loop), (E) 8 (second loop), (F) 9 (third loop) and in the presence of $\mathrm{KCl}$ (G) 7 (first loop), (H) 8 (second loop), (I) 9 (third loop). Peak 'a' corresponds to benzofuran boronic acid substrate. 

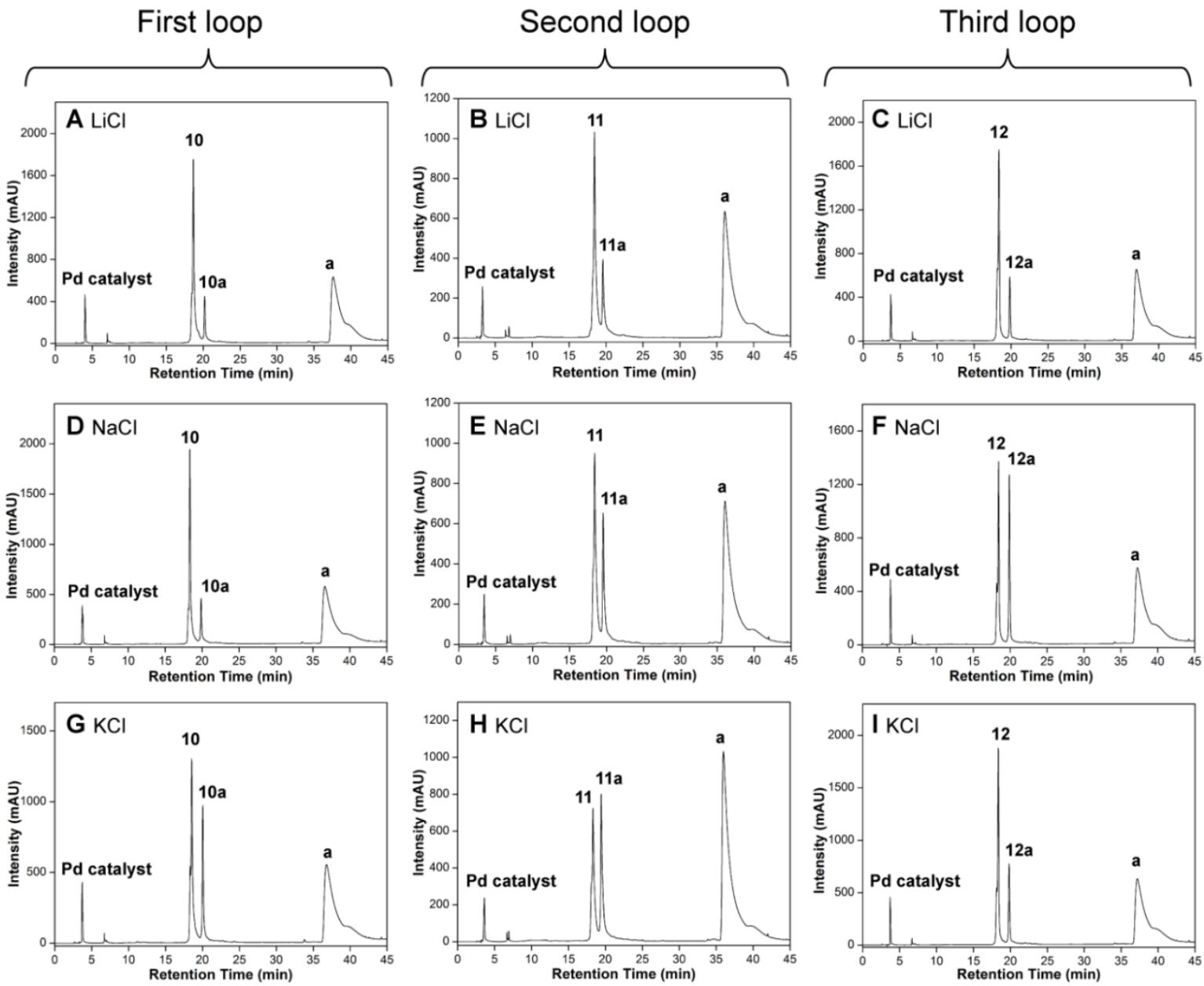

Figure S7. RP-HPLC chromatograms of reaction mixtures of postsynthetic Suzuki-Miyaura crosscoupling reactions on IdU-modified H-Telo-24 (IdU 1 incorporated at the $2^{\text {nd }}$ dT position of each loop) DNA ON in the presence of $\mathrm{LiCl}$ (A) 10 (first loop), (B) 11 (second loop), (C) 12 (third loop); in the presence of $\mathrm{NaCl}$ (D) $\mathbf{1 0}$ (first loop), (E) $\mathbf{1 1}$ (second loop), (F) $\mathbf{1 2}$ (third loop) and in the presence of $\mathrm{KCl}$ (G) $\mathbf{1 0}$ (first loop), (H) 11 (second loop), (I) 12 (third loop). Peak 'a' corresponds to benzofuran boronic acid substrate. 

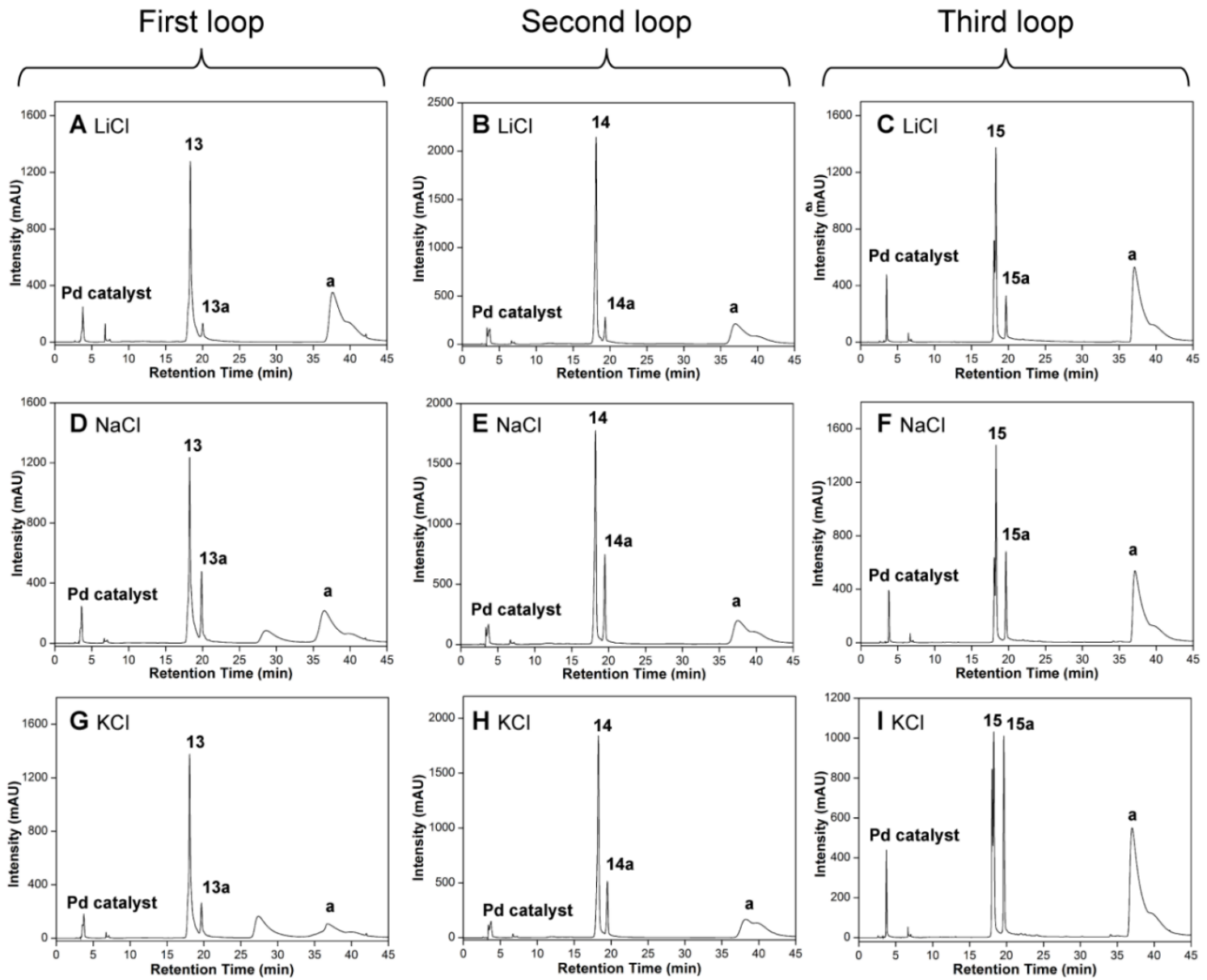

Figure S8. RP-HPLC chromatograms of reaction mixtures of postsynthetic Suzuki-Miyaura crosscoupling reactions on IdU-modified H-Telo-25 (IdU 1 incorporated at the $2^{\text {nd }}$ dT position of each loop) DNA ON in the presence of $\mathrm{LiCl}$ (A) 13 (first loop), (B) 14 (second loop), (C) 15 (third loop); in the presence of $\mathrm{NaCl}$ (D) 13 (first loop), (E) 14 (second loop), (F) 15 (third loop) and in the presence of $\mathrm{KCl}$ (G) 13 (first loop), (H) 14 (second loop), (I) 15 (third loop). Peak 'a' corresponds to benzofuran boronic acid substrate. 

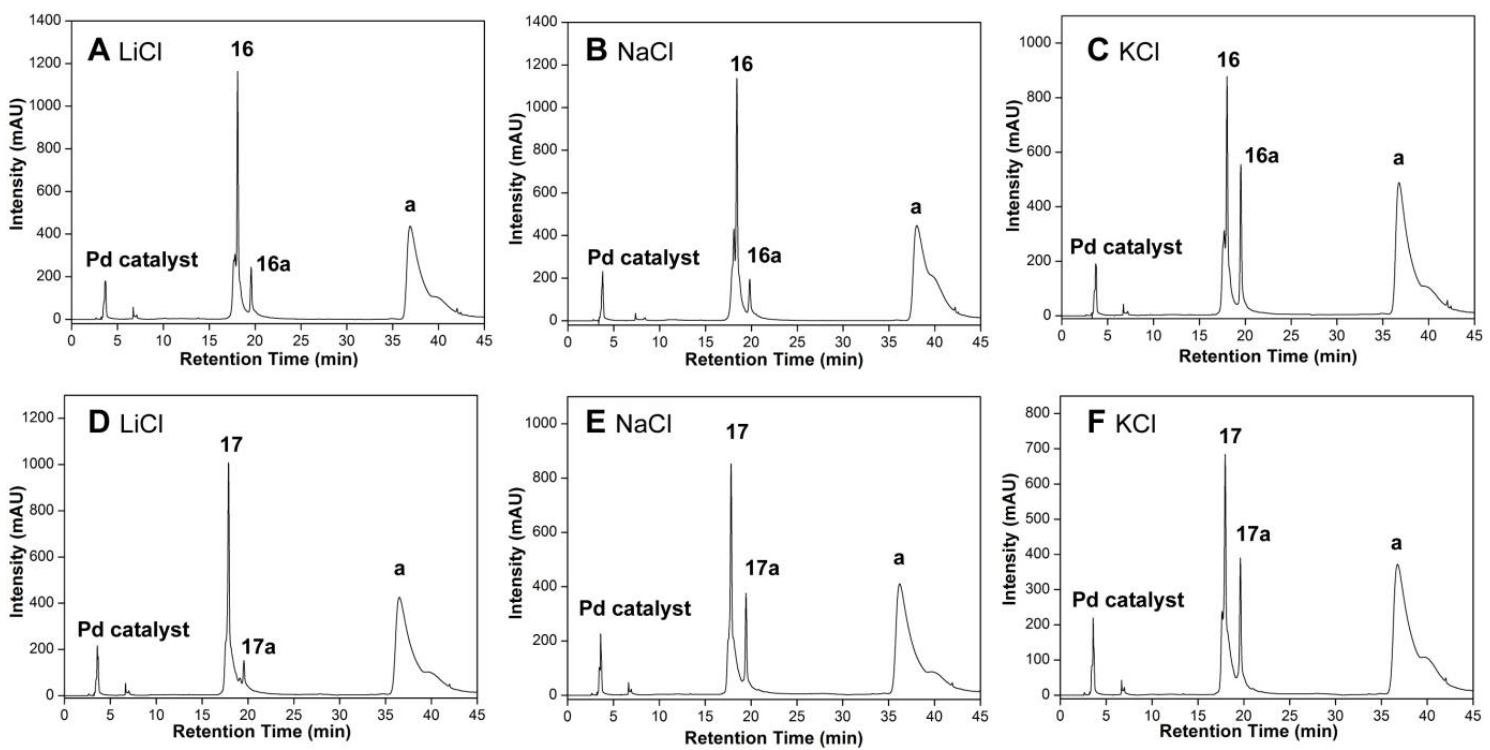

Figure S9. RP-HPLC chromatograms of reaction mixtures of post-synthetic Suzuki-Miyaura crosscoupling reactions on IdU-modified DNA ON 16 in the presence of $(\mathbf{A}) \mathrm{LiCl},(\mathbf{B}) \mathrm{NaCl},(\mathbf{C}) \mathrm{KCl}$ and 17 in presence of (D) $\mathrm{LiCl},(\mathbf{E}) \mathrm{NaCl},(\mathbf{F}) \mathrm{KCl}$. Peak 'a' corresponds to benzofuran boronic acid substrate. 

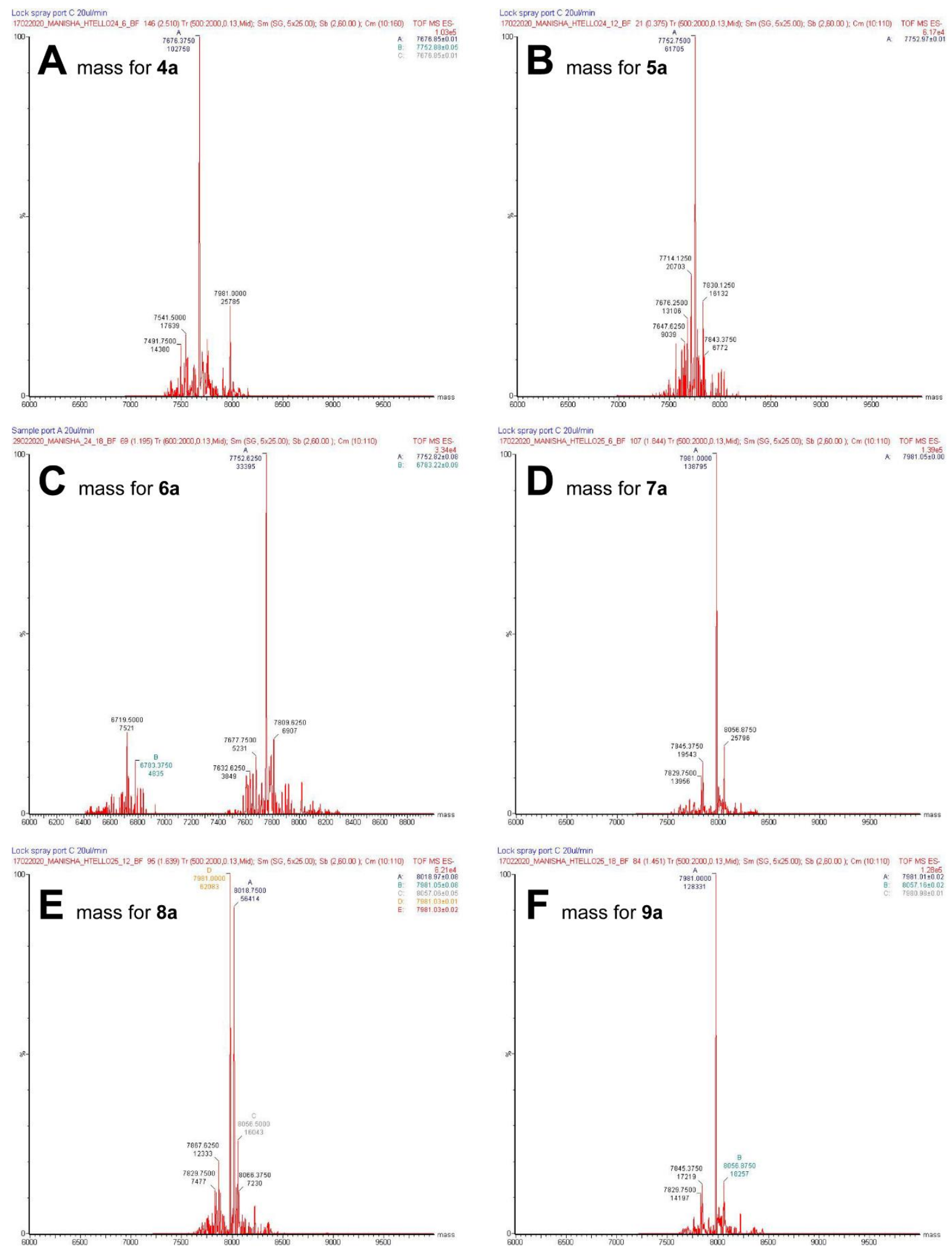

Figure S10. ESI-MS spectra of BFdU-modified H-Telo DNA ONs (A) 4a, (B) 5a, (C) 6a, (D) 7a, (E) 8, (F) 9a. See section 5 for details, Table 2 and Table S2 for isolated yields and mass data, respectively. 

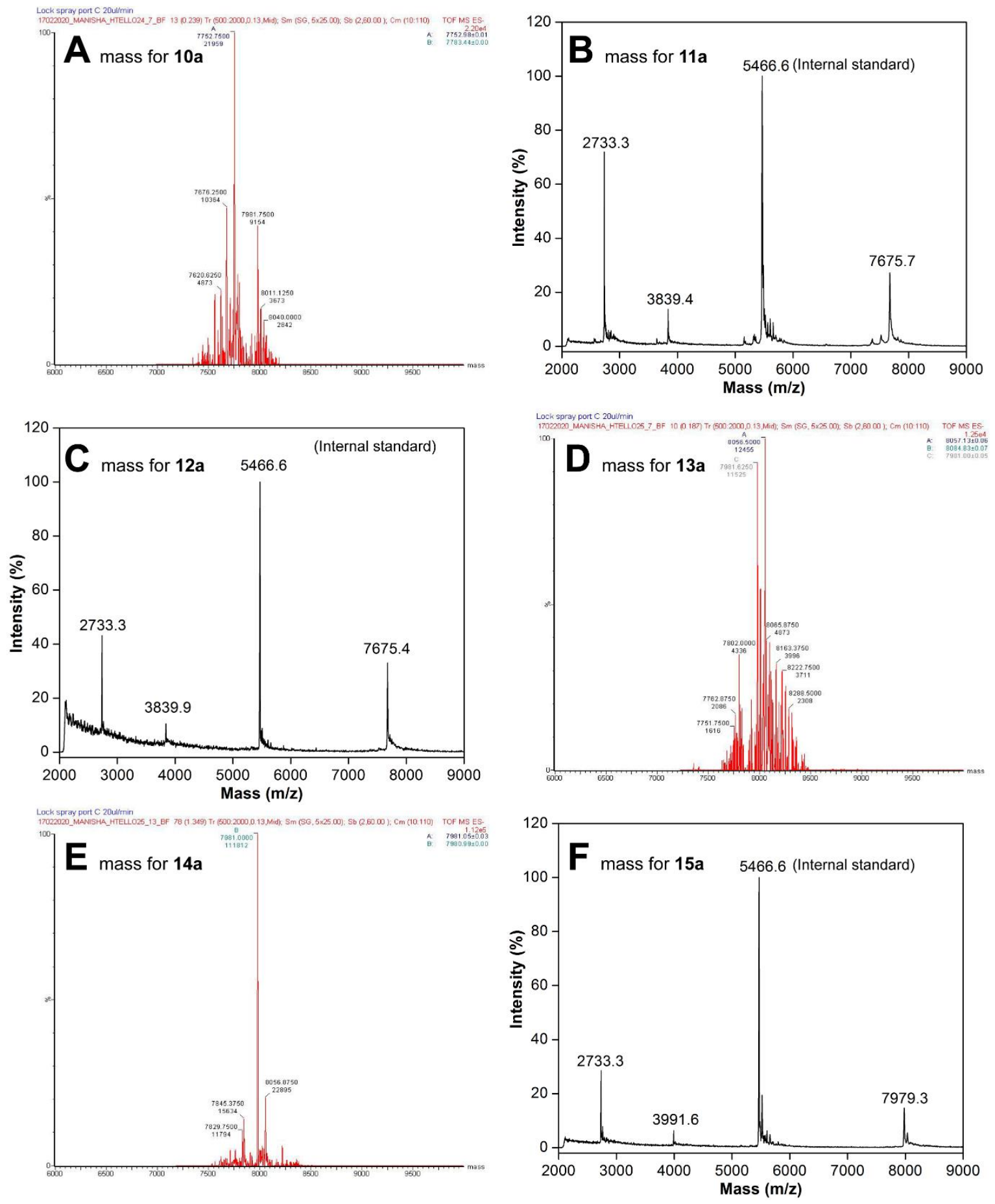

Figure S11. ESI-MS spectra of BFdU-modified H-Telo DNA ONs (A) 10a, (D) 13a, (E) 14a. MALDI-TOF spectra of BFdU-modified H-Telo DNA ONs (B)11a, (C) 12a, (F) 15a. See section 5 for details and Table 2 and Table S2 for isolated yields and mass data, respectively. 

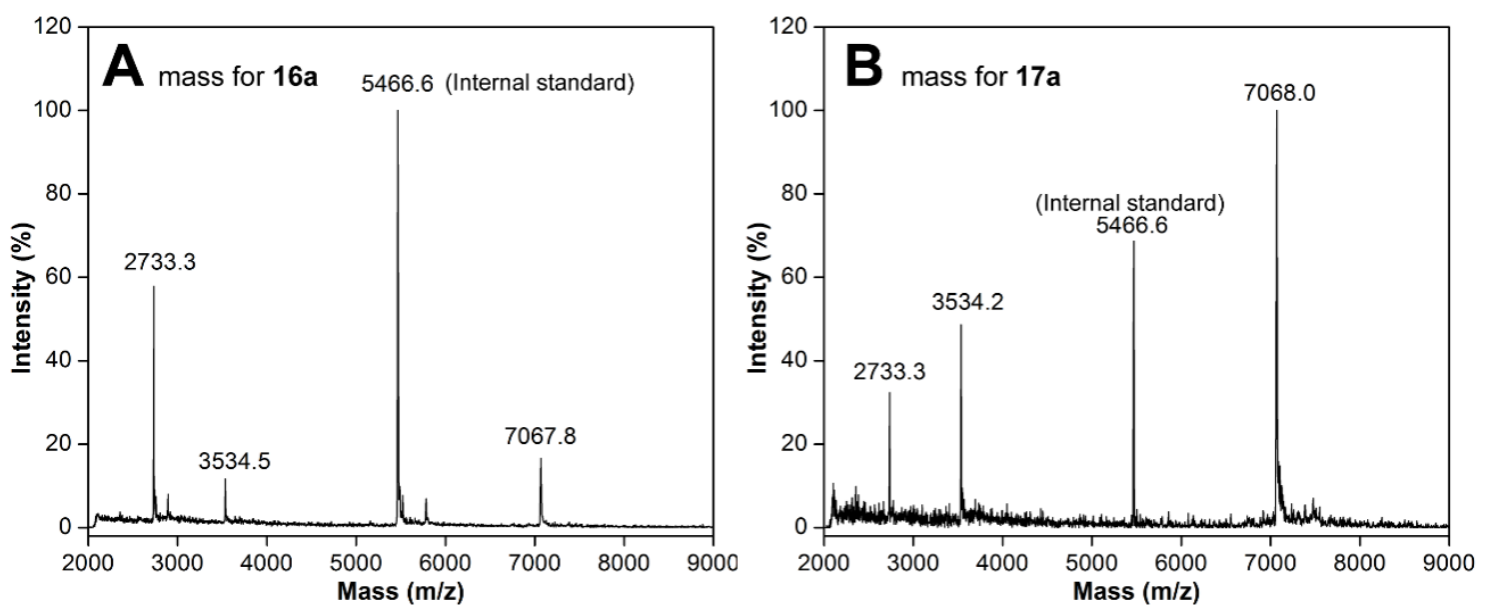

Figure S12. MALDI-TOF spectra of BFdU-modified H-Telo DNA ONs (A) 16a, (B) 17a. See section 5 and Table $\mathrm{S} 2$ for details

Table S2. ESI-MS and MALDI-TOF mass data of BFdU-modified DNA ONs (4a-17a).

\begin{tabular}{llll}
\hline $\begin{array}{l}\text { BF-modified } \\
\text { DNA ONs }\end{array}$ & $\varepsilon_{260}\left(\mathrm{M}^{-1} \mathrm{~cm}^{-1}\right)^{[\mathrm{a}]}$ & Calculated mass & Observed mass \\
\hline $\mathbf{4 a}$ & 248213 & 7676.0 & $7676.8^{[\mathrm{c}]}$ \\
$\mathbf{5 a}$ & 248213 & 7676.0 & $7753.0^{[\mathrm{c}]}(\mathrm{M}+2 \mathrm{~K}-3 \mathrm{H})^{-}$ \\
$\mathbf{6 a}$ & 248213 & 7676.0 & $7752.9^{[\mathrm{cc}]}(\mathrm{M}+2 \mathrm{~K}-3 \mathrm{H})^{-}$ \\
$\mathbf{7 a}$ & 257013 & 7980.0 & $7981.0^{[\mathrm{c}]}$ \\
$\mathbf{8 a}$ & 257013 & 7980.0 & $7981.0^{[\mathrm{c}]}$ \\
$\mathbf{9 a}$ & 257013 & 7980.0 & $7981.0^{[\mathrm{c}]}$ \\
$\mathbf{1 0 a}$ & 248213 & 7676.0 & $7753.0^{[\mathrm{c}]}(\mathrm{M}+2 \mathrm{~K}-3 \mathrm{H})^{-}$ \\
$\mathbf{1 1 a}$ & 248213 & 7676.0 & $7675.7^{[\mathrm{b}]}$ \\
$\mathbf{1 2 a}$ & 248213 & 7676.0 & $7675.4^{[\mathrm{b}]}$ \\
$\mathbf{1 3 a}$ & 257013 & 7980.0 & $8057.0^{[\mathrm{c}]}(\mathrm{M}+2 \mathrm{~K}-3 \mathrm{H})^{-}$ \\
$\mathbf{1 4 a}$ & 257013 & 7980.0 & $7981.0^{[\mathrm{c}]}$ \\
$\mathbf{1 5 a}$ & 257013 & 7980.0 & $7979.3^{[\mathrm{b}]}$ \\
$\mathbf{1 6 a}$ & 232413 & 7067.6 & $7067.6^{[\mathrm{b}]}$ \\
$\mathbf{1 7 a}$ & 232413 & 7067.6 & $7068.0^{[\mathrm{b}]}$ \\
\hline
\end{tabular}

${ }^{[a]}$ Molar absorption coefficient of benzofuran modified ONs was determined by using OligoAnalyzer 3.1 , which was used for the determination of the concentration of modified ONs. The extinction coefficient of nucleoside 5-benzofuran-2'-deoxyuridine (BFdU, $\left.\varepsilon_{260}=12613 \mathrm{M}^{-1} \mathrm{~cm}^{-1}\right)^{\mathrm{S} 2}$ was used in place of thymidine $\left(\varepsilon_{260}=8700 \mathrm{M}^{-1} \mathrm{~cm}^{-1}\right)$.

${ }^{[b]}$ MALDI-TOF. ${ }^{[c]}$ ESI-MS. 


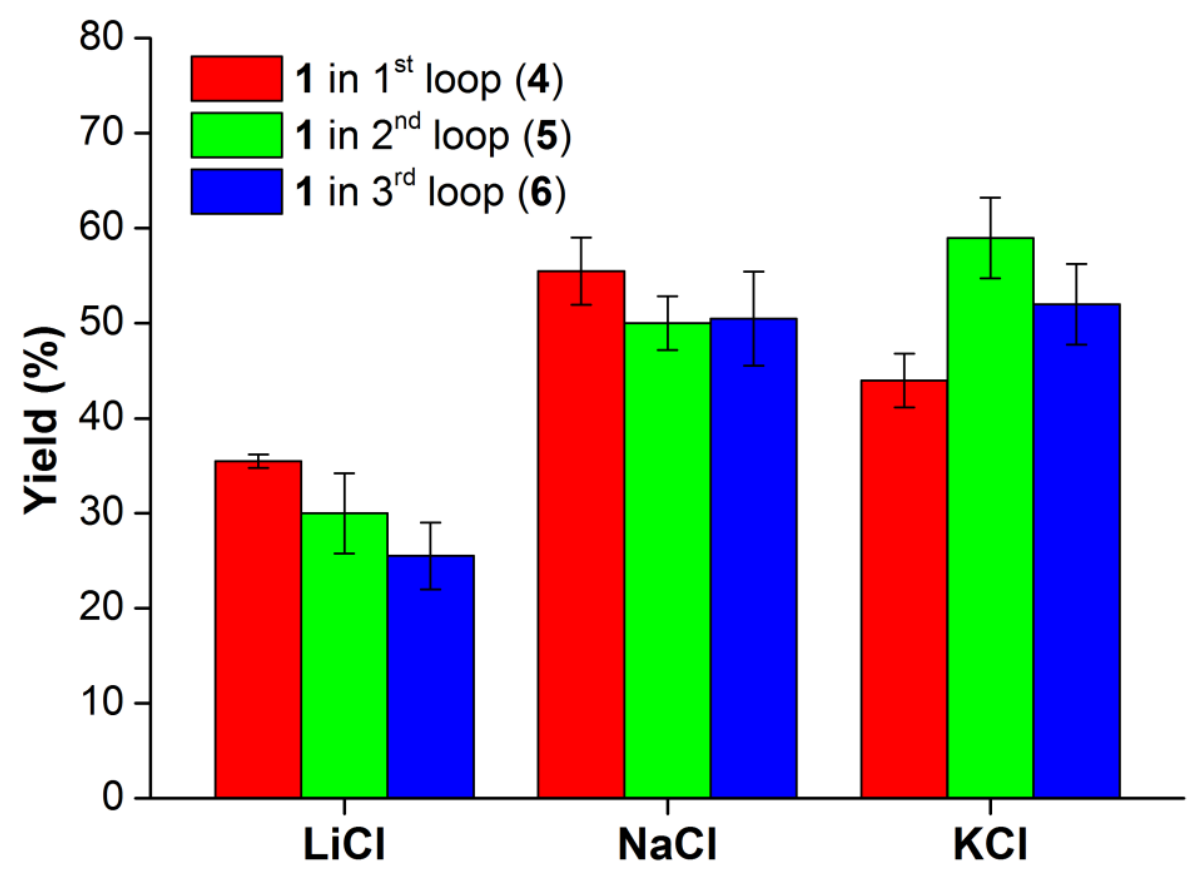

Figure S13. Bar diagram of isolated yields of cross-coupled products (4a-6a) obtained from reactions between IdU-labeled ONs (4-6) and benzofuran boronic acid substrate (a) in the presence of different ions. Individual reactions were performed in duplicate.
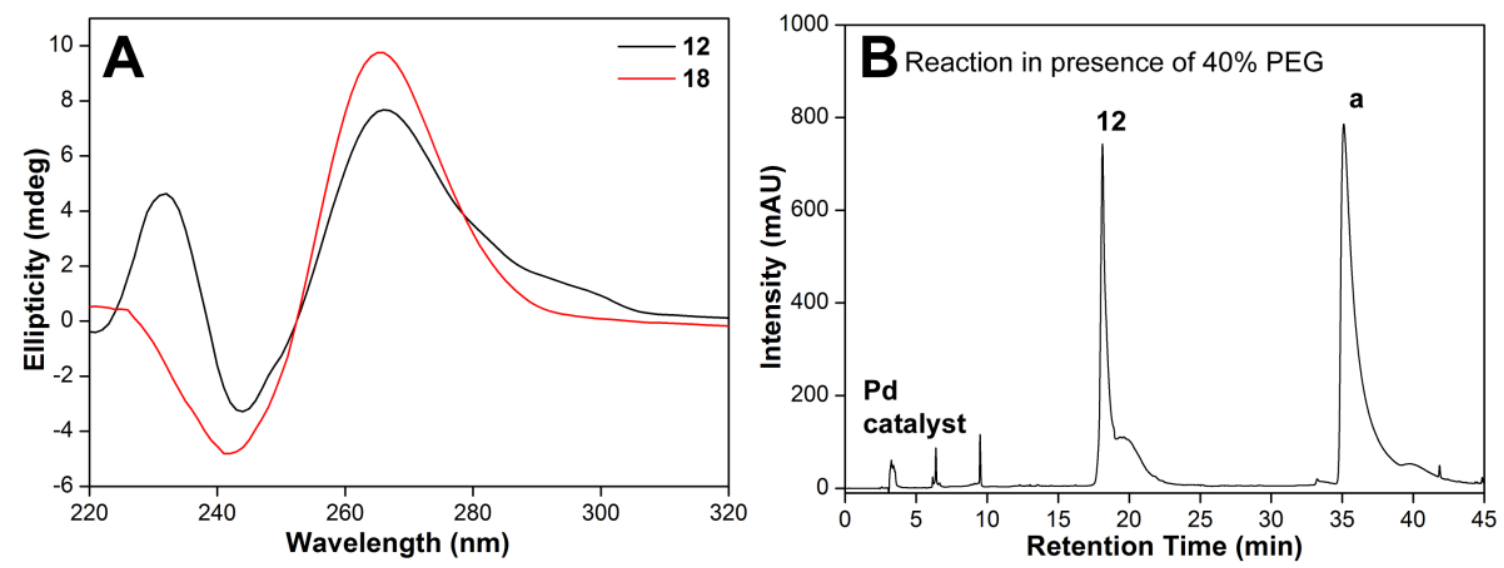

Figure S14. (A) CD profile of IdU-modified H-Telo DNA ON 12 and control unmodified H-Telo DNA ON 18 in $50 \mathrm{mM}$ Tris-HCl buffer (pH 8.5) containing 40\% PEG (200) and $100 \mathrm{mM} \mathrm{KCl}$ and 20\% DMSO. (B) RP-HPLC chromatogram for the reaction mixture of Suzuki-Miyaura crosscoupling on parallel GQ formed by DNA ON 12. Peak 'a' corresponds to benzofuran boronic acid substrate. 

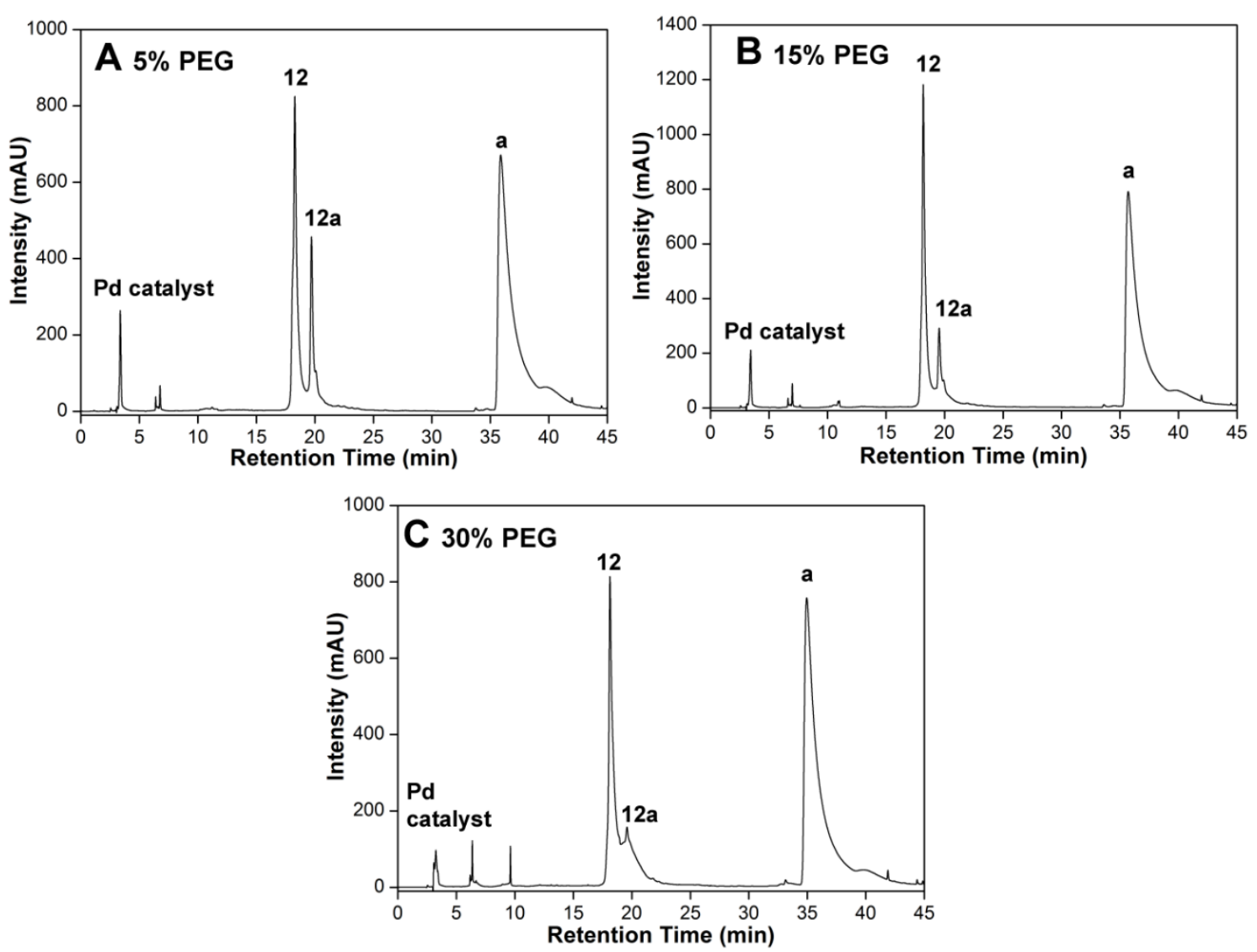

Figure S15. HPLC chromatograms of the reaction mixtures of the Suzuki-Miyaura cross-coupling on parallel GQ topology formed by IdU-modified H-Telo DNA ON 12 with boronic acid (a) as a function of increasing percentage of PEG (A) 5\%, (B) 15\% and (C) 30\%. Peak 'a' corresponds to benzofuran boronic acid substrate. 

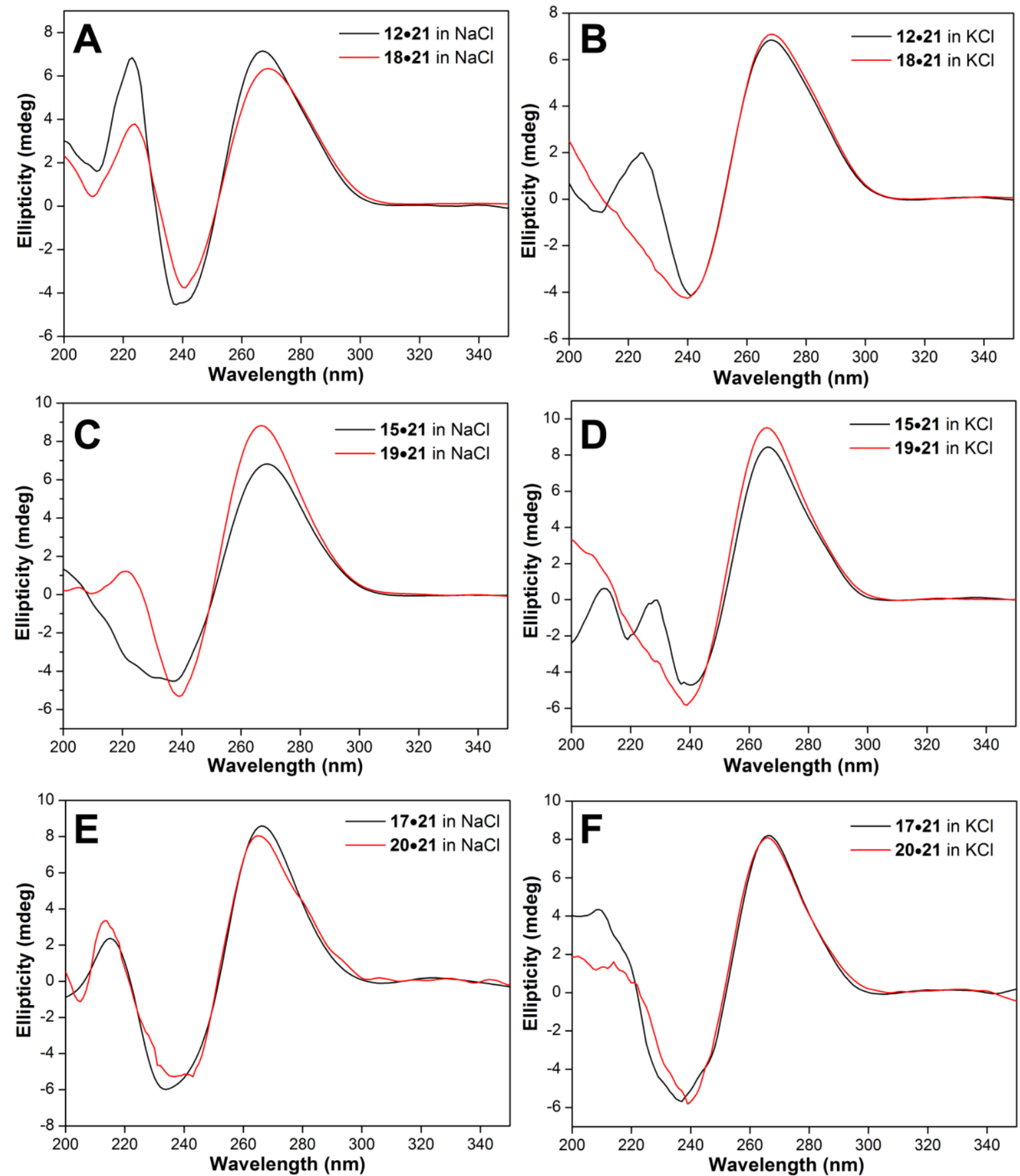

Figure S16. CD spectra of IdU-modified DNA duplexes $(\mathbf{1 2 \cdot 2 1}, \mathbf{1 5} \cdot \mathbf{2 1}, \mathbf{1 7} \cdot \mathbf{2 1}, 8 \mu \mathrm{M}$, black lines) and control DNA duplexes $(\mathbf{1 8 \cdot 2 1}, \mathbf{1 9 \cdot 2 1}, \mathbf{2 0} \cdot \mathbf{2 1}, 8 \mu \mathrm{M}$, red lines) and in Tris-HCl buffer $(50 \mathrm{mM}, \mathrm{pH}=$ $8.5)$ containing either $\mathrm{NaCl}$ or $\mathrm{KCl}$ and $20 \%$ DMSO. 

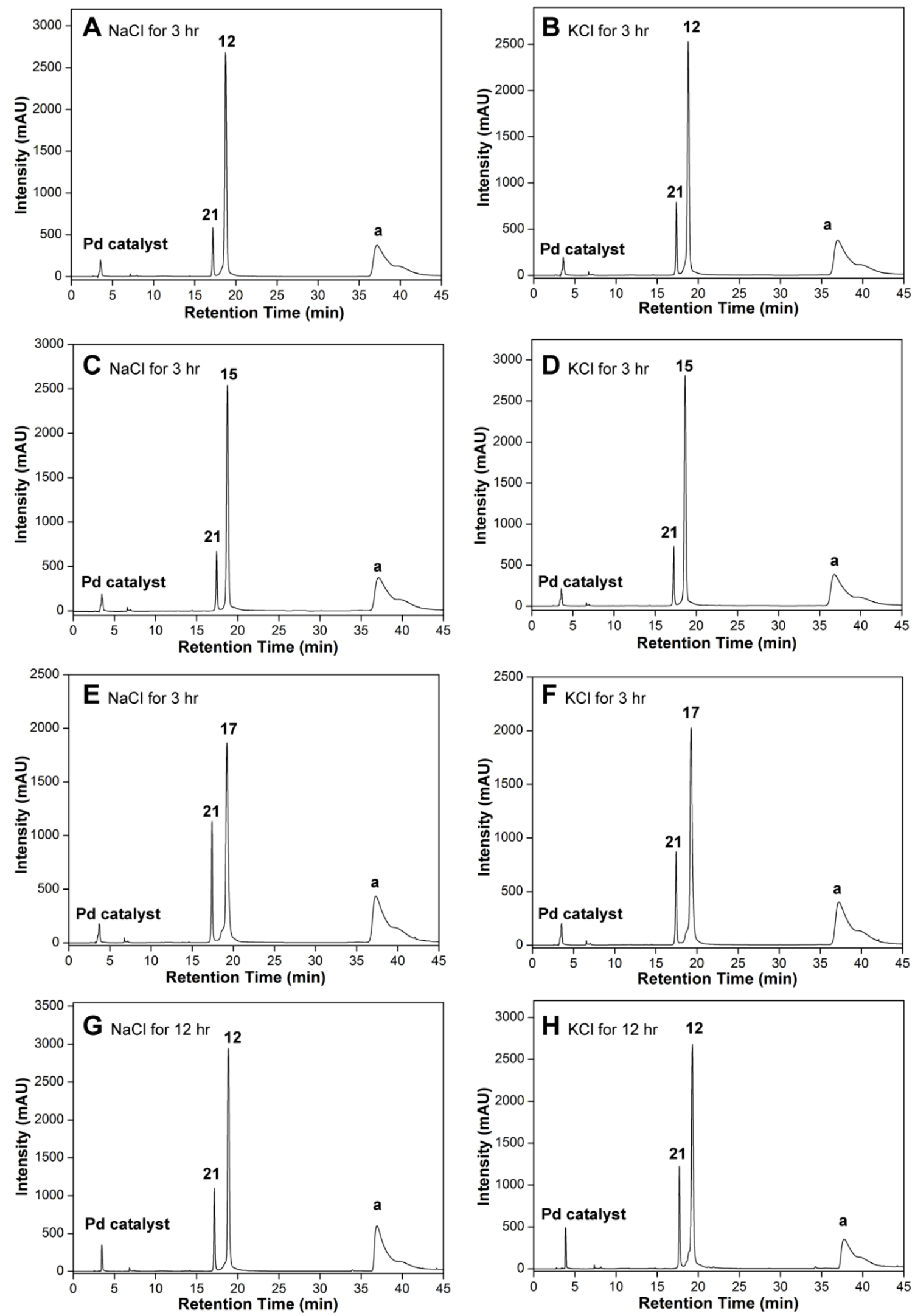

Figure S17. RP-HPLC chromatograms showing no detectable reaction products between benzofuran boronic acid and IdU-modified DNA duplexes $(\mathbf{1 2} \cdot \mathbf{2 1}, \mathbf{1 5} \cdot \mathbf{2 1}, \mathbf{1 7} \cdot \mathbf{2 1})$ composed of G-rich DNA ON 12/15/17 and its complementary C-rich DNA ON 21. Peak 'a' corresponds to benzofuran boronic acid substrate. 


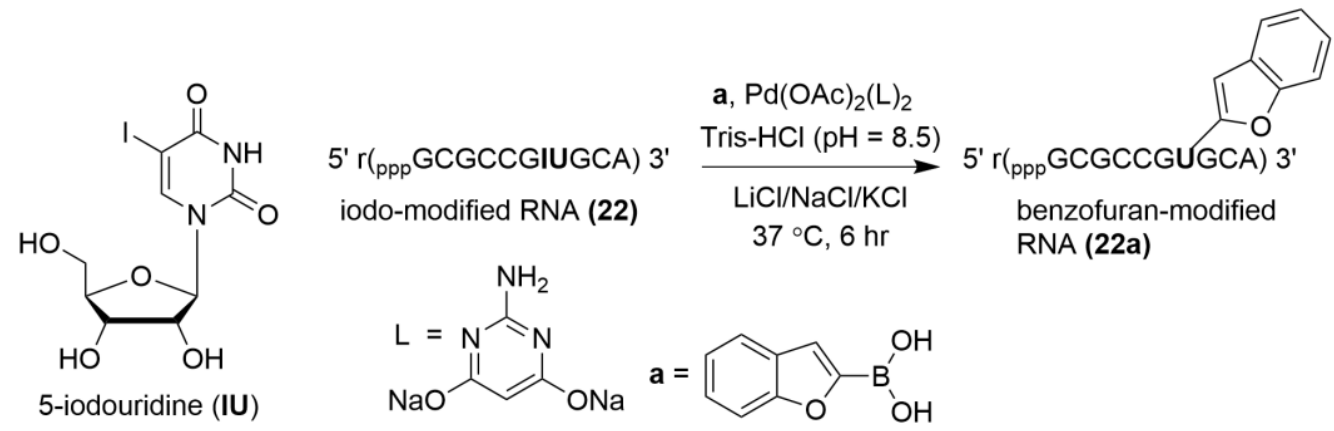

Scheme S1. Suzuki-Miyaura cross-coupling reaction on IU-modified ON 22 with benzofuran boronic acid (a) in the presence of salt $(\mathrm{LiCl} / \mathrm{NaCl} / \mathrm{KCl})$.
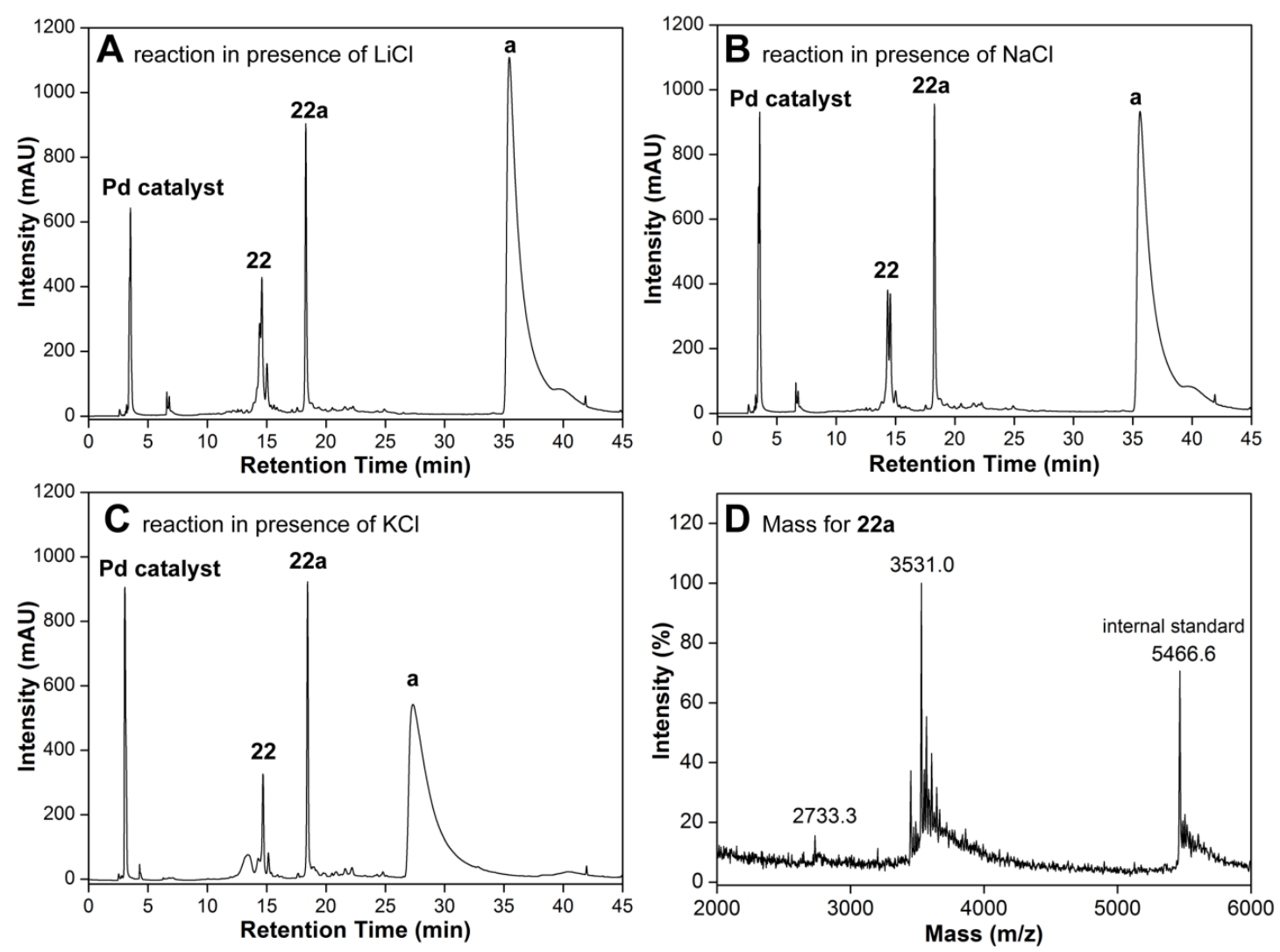

Figure S18. RP-HPLC chromatograms of reaction mixtures of Suzuki-Miyaura cross-coupling between IU-modified ON 22 and benzofuran boronic acid (a) in the presence of $\mathrm{LiCl}(\mathbf{A}), \mathrm{NaCl}(\mathbf{B})$ and $\mathrm{KCl}(\mathbf{C})$. 22a correspond to cross-coupled RNA ON product. Running conditions same as above. (D) MALDI-TOF mass spectrum of cross-coupled RNA ON product 22a. Calcd. mass for crosscoupled ON product 22a: [M] ${ }^{+} 3531.0$; found: $[\mathrm{M}]^{+}$3531.0. MALDI-TOF spectra are calibrated with respect to the +1 and +2 ion of an internal 18-mer DNA ON standard (m/z for +1 and +2 ion are 5466.6 and 2733.3 respectively). Peak 'a' corresponds to benzofuran boronic acid substrate. 
Table S3. Yields for cross-coupled ON product 22a obtained by Suzuki-Miyaura reaction between IU-modified transcript 22 and benzofuran boronic acid $\mathbf{a} .{ }^{[a]}$

\begin{tabular}{ccc}
\hline salt & $\begin{array}{c}\text { isolated yield } \\
\text { for 22a (nmol) }\end{array}$ & $\begin{array}{c}\text { isolated yield } \\
\text { for 22a }(\%)\end{array}$ \\
\hline $\mathrm{LiCl}$ & 1.85 & 37 \\
$\mathrm{NaCl}$ & 1.97 & 39 \\
$\mathrm{KCl}$ & 1.63 & 33 \\
\hline
\end{tabular}

${ }^{[a]}$ Reactions were performed on a 5 nmole scale of IU-modified ON 22. Concentration and yield of the products were calculated using the molar absorption coefficient $\left(\varepsilon_{260}\right)$ of the ON product 22a $(98553$ $\left.\mathrm{M}^{-1} \mathrm{~cm}^{-1}\right){ }^{\mathrm{S} 3}$

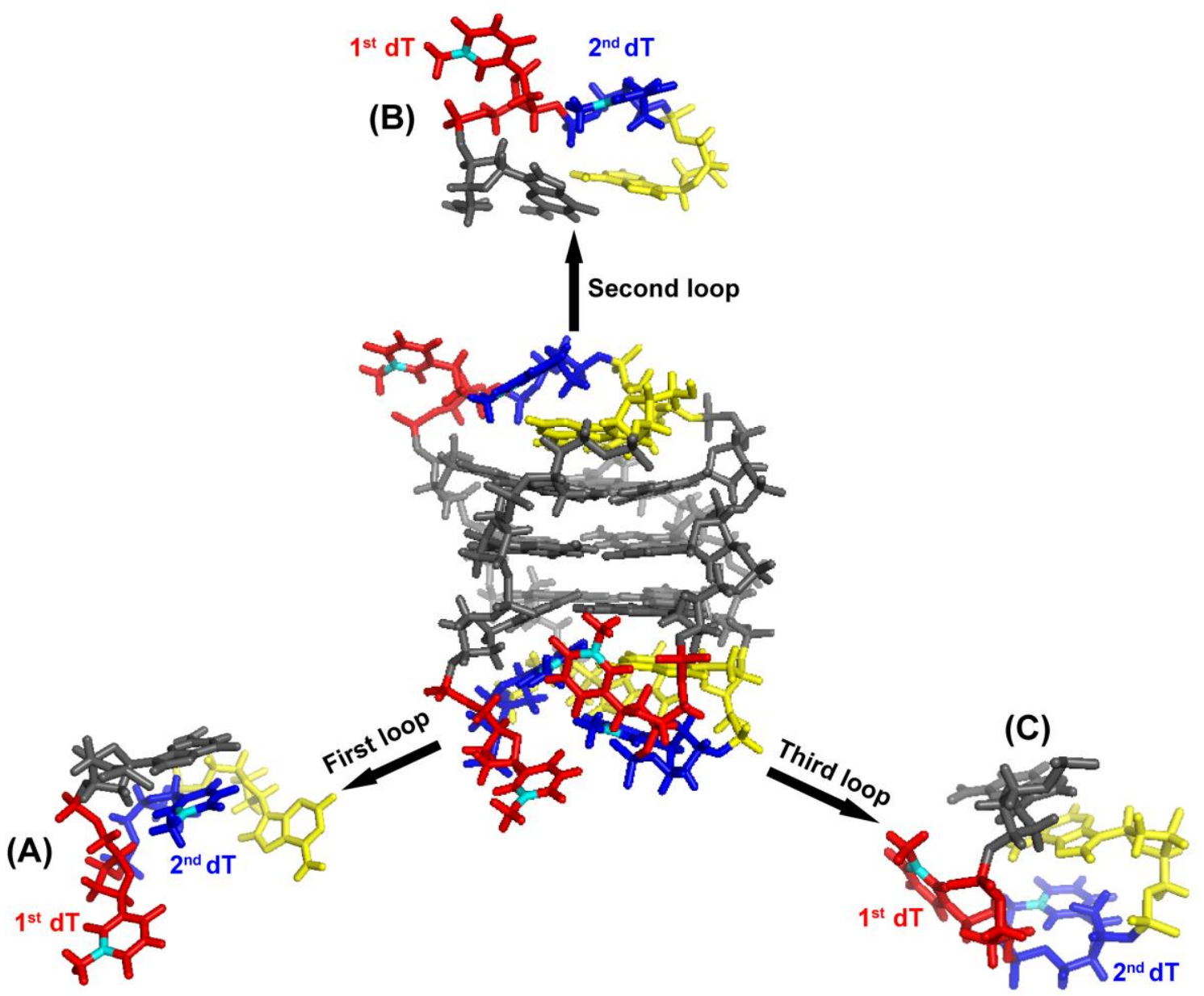

Figure S19. NMR structure of an antiparallel GQ conformation of a native H-Telo ON 20 in $\mathrm{Na}^{+}$ solution (PDB ID: 143D). ${ }^{\mathrm{S} 4}$ A close-up view of stacking interactions of the nucleobases in the first (A), second (B) and third loop (C) regions is shown. dG is shown in grey, dA is shown in yellow, first dT of each loop is shown in red and second dT of each loop is shown in blue. C5 position of dTs is shown in cyan color. 


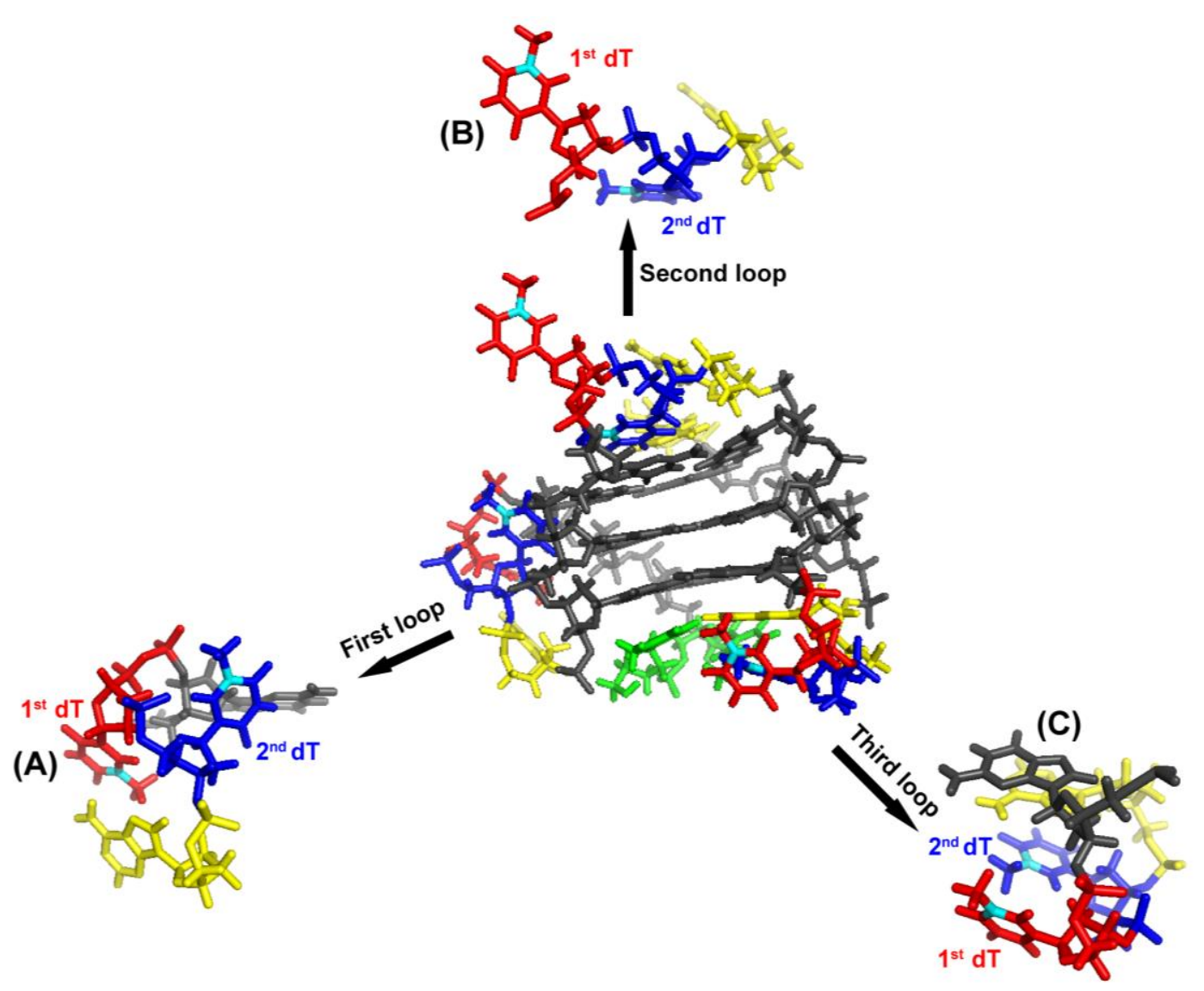

Figure S20. NMR structure of Hybrid 1 GQ conformation of a native H-Telo ON 18 in $\mathrm{K}^{+}$solution (PDB ID: 2GKU). ${ }^{\mathrm{S} 5} \mathrm{~A}$ close-up view of stacking interactions of the nucleobases in the first (A), second $(\mathbf{B})$ and third loop $(\mathbf{C})$ regions is shown. $\mathrm{dG}$ is shown in grey, $\mathrm{dA}$ is shown in yellow, first dT of each loop is shown in red and second dT of each loop is shown in blue. $5^{\prime}$ terminal TT residue is shown in the green. C5 position of dTs is shown in cyan color.
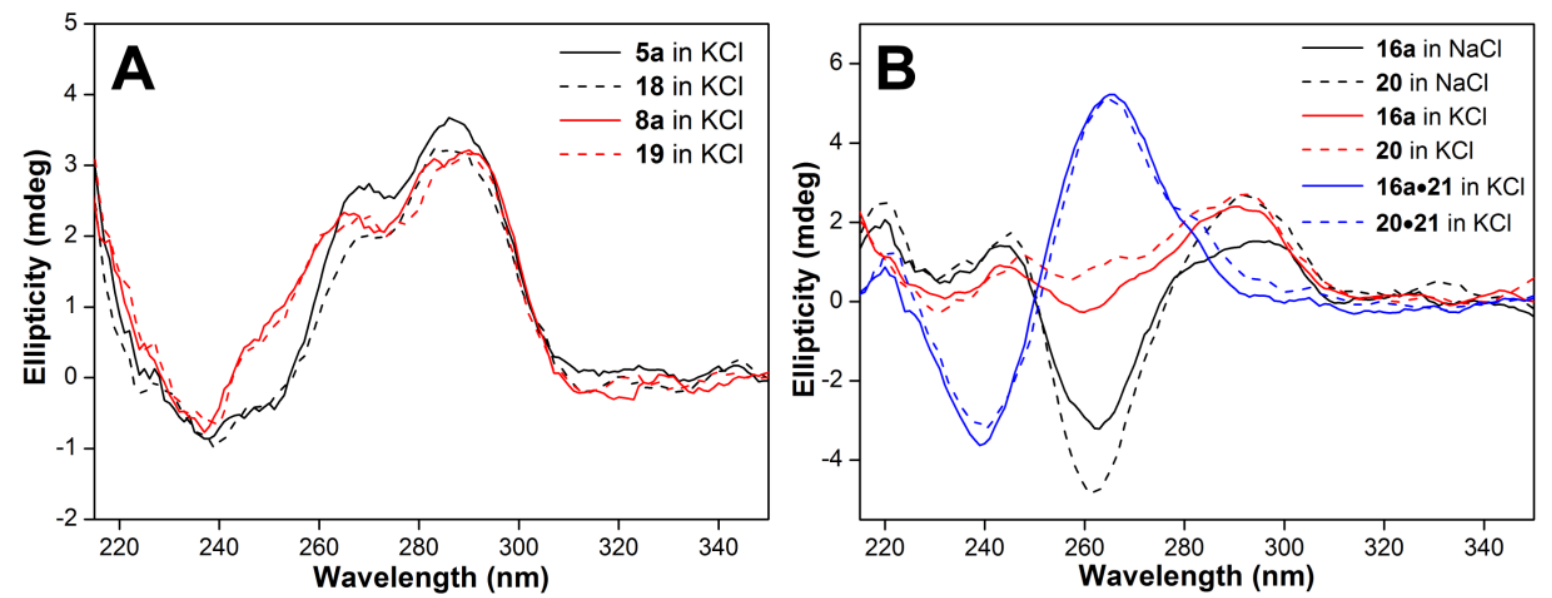

Figure S21. CD spectra of (A) GQs of BFdU-modified H-Telo DNA ONs 5a (hybrid 1), 8a (hybrid 2) and respective unmodified H-Telo DNA ONs 18 and 19 in KCl. (B) GQs of BFdU-modified HTelo DNA ON 16a, unmodified H-Telo DNA ON 20 and corresponding duplexes $(\mathbf{1 6 a} \cdot \mathbf{2 1}, \mathbf{2 0} \cdot \mathbf{2 1})$ in different ionic conditions. $\mathrm{CD}$ spectra of ON samples $(5 \mu \mathrm{M})$ were recorded in $10 \mathrm{mM}$ Tris-HCl buffer (pH 7.5) containing $100 \mathrm{mM} \mathrm{KCl}$ or $100 \mathrm{mM} \mathrm{NaCl}$. 16a and 20 in $\mathrm{NaCl}$ forms antiparallel GQ structure (black lines) and in $\mathrm{KCl}$ hybrid type structures (red lines). Duplexes are shown in blue lines. 


\section{NMR and mass spectra}

${ }^{1} \mathrm{H}$ NMR (400 MHz) of compound 2 in $\mathrm{CDCl}_{3}$ containing $0.3 \mathrm{v} / \mathrm{v} \%$ of TMS. Triplet at $1.26 \mathrm{ppm}$ and quartet at $2.90 \mathrm{ppm}$ correspond to $\mathrm{Et}_{3} \mathrm{~N}$.

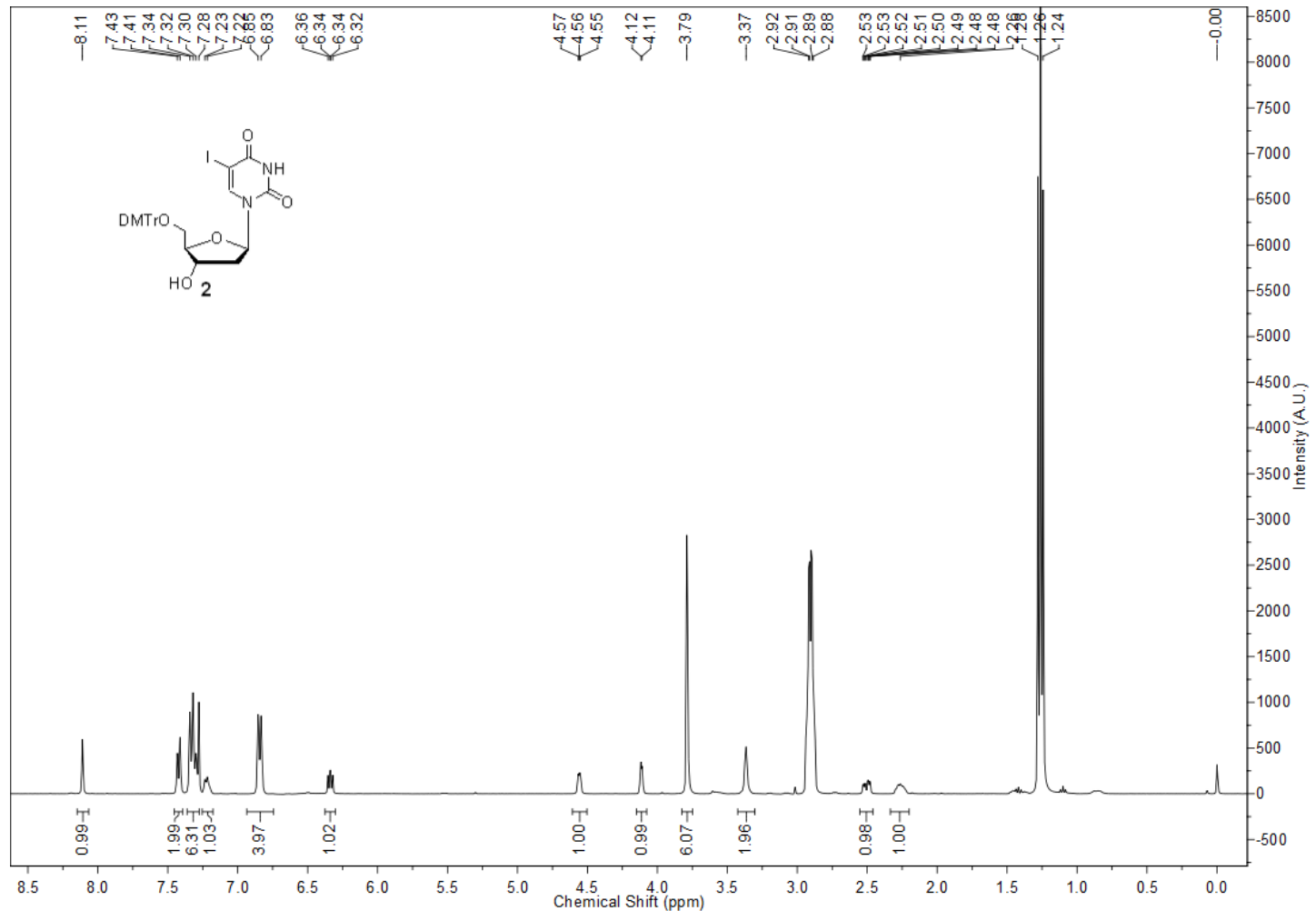

${ }^{13} \mathrm{C}$ NMR $(100 \mathrm{MHz})$ of compound 2 in $\mathrm{CDCl}_{3}$ containing $0.3 \mathrm{v} / \mathrm{v} \%$ of TMS. Peaks at $9.58 \mathrm{ppm}$ and $45.83 \mathrm{ppm}$ correspond to $\mathrm{Et}_{3} \mathrm{~N}$.

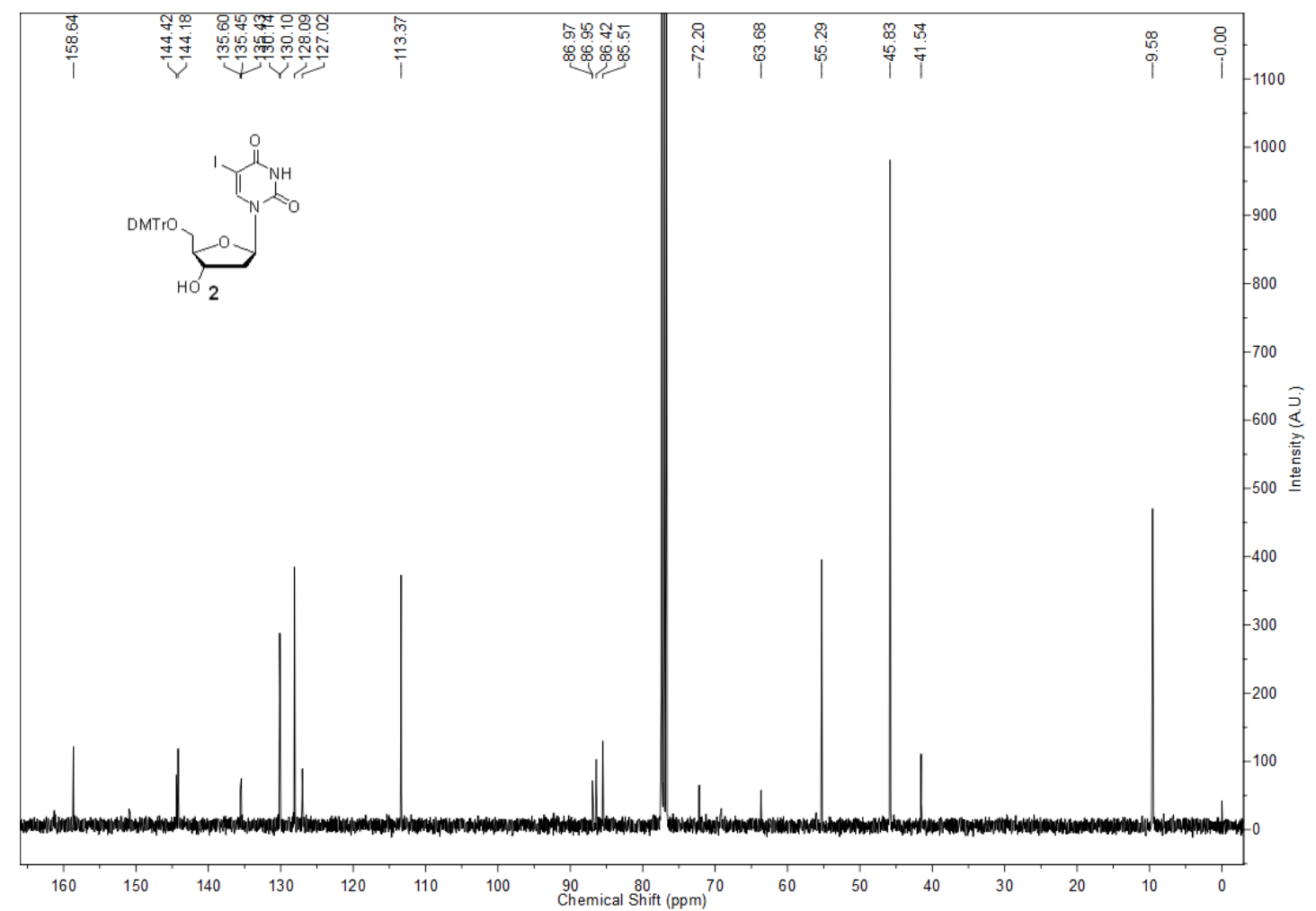


${ }^{1} \mathrm{H}$ NMR (400 MHz) of compound 3 in $\mathrm{CDCl}_{3}$ containing $0.3 \mathrm{v} / \mathrm{v} \%$ of TMS. (diastereomers ratio = $1: 0.5)$.

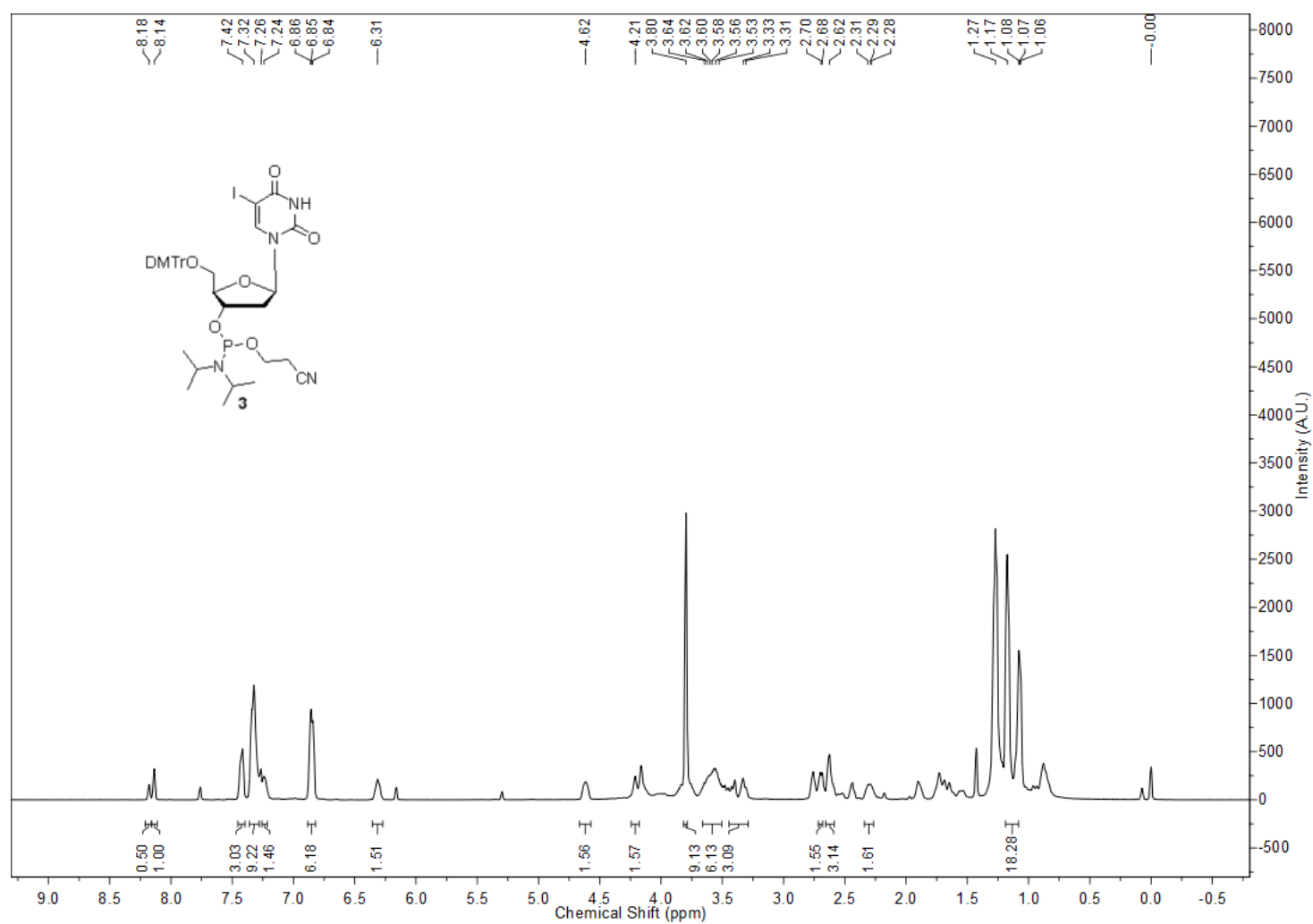

${ }^{31} \mathrm{P}$ NMR (162 MHz) of compound $\mathbf{3}$ in $\mathrm{CDCl}_{3}$.

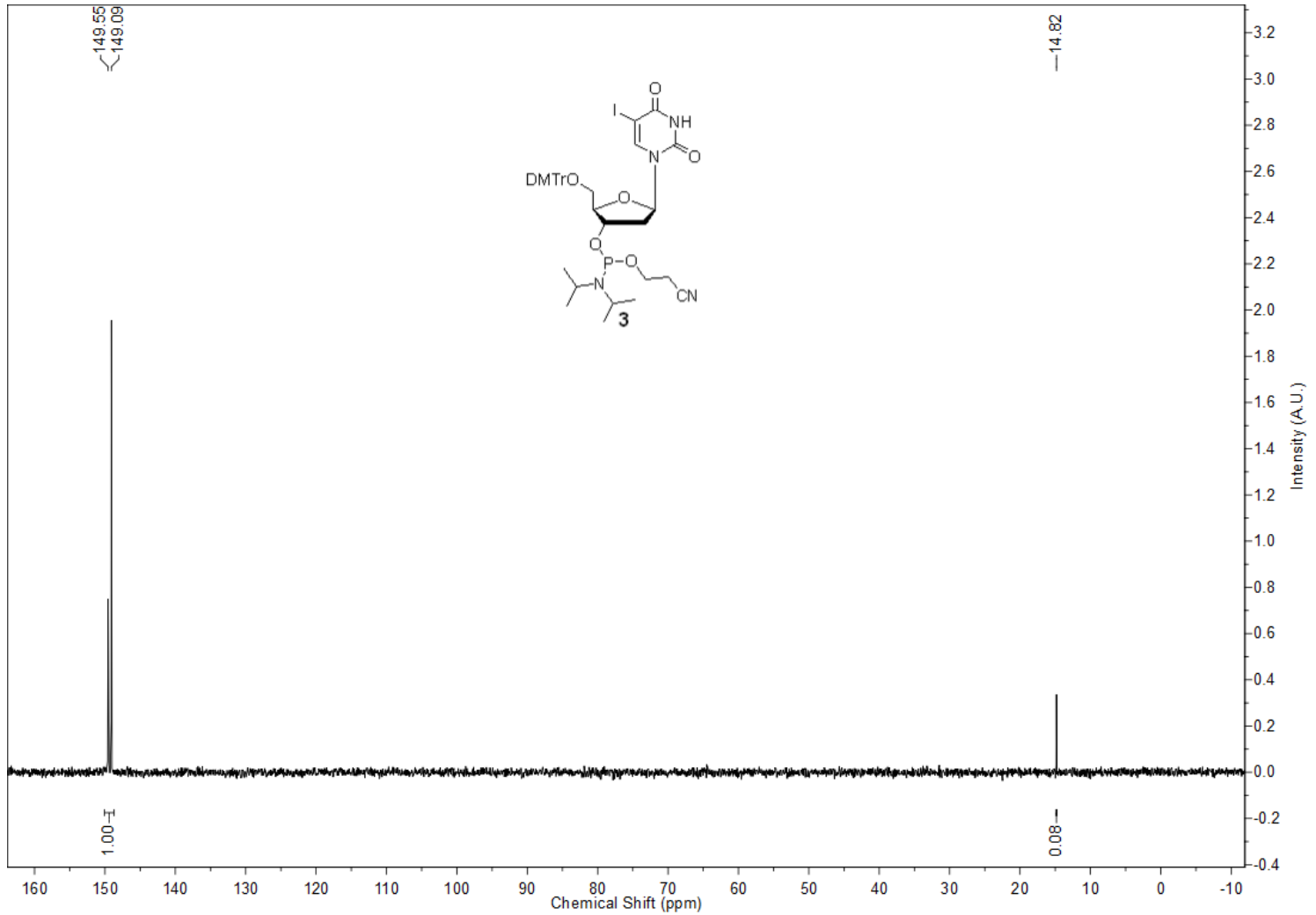


ESI-MS of compound 3

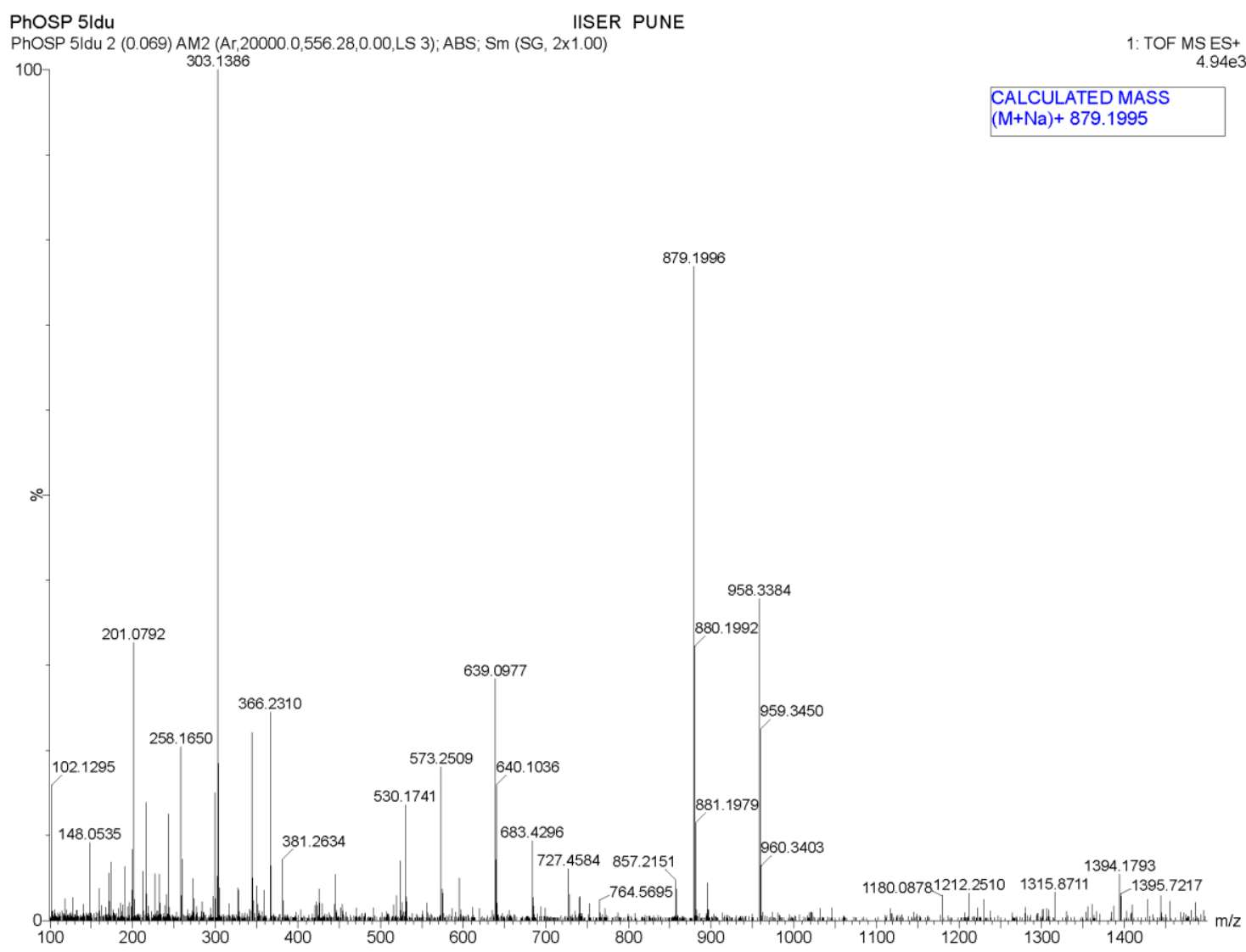

\section{References}

S1. Rospigliosi, A., Ehlich, R., Hoerber, H., Middelberg, A., and Moggridge, G. (2007) Electron transfer of plurimodified DNA SAMs. Langmuir 23, 8264-8271.

S2. Tanpure, A. A., and Srivatsan, S. G. (2012) Synthesis and photophysical characterisation of a fluorescent nucleoside analogue that signals the presence of an abasic Site in RNA. ChemBioChem 13, 2392-2399.

S3. Walunj, M. B., Tanpure, A. A., and Srivatsan, S. G. (2018) Posttranscriptional labeling by using Suzuki-Miyaura cross-coupling generates functional RNA probes. Nucleic Acids Res. 46, e65.

S4. Wang, Y., and Patel, D. J. (1993) Solution structure of the human telomeric repeat $\mathrm{d}\left[\mathrm{AG}_{3}\left(\mathrm{~T}_{2} \mathrm{AG}_{3}\right)_{3}\right]$ G-tetraplex. Structure 1, 263-282.

S5. Luu, K. N., Phan, A. T., Kuryavyi, V., Lacroix, L., and Patel, D. J. (2006) Structure of the human telomere in $\mathrm{K}^{+}$solution: an intramolecular $(3+1)$ G-quadruplex scaffold. $J . A m$. Chem. Soc. 128, 9963-9970. 